\title{
Learning-Dependent and -Independent Enhancement of Mitral/Tufted Cell Glomerular Odor Responses Following Olfactory Fear Conditioning in Awake Mice
}

\author{
ㄱordan M. Ross and Max L. Fletcher \\ Department of Anatomy and Neurobiology, University of Tennessee Health Science Center, Memphis, Tennessee, 38134
}

\begin{abstract}
Associative fear learning produces fear toward the conditioned stimulus (CS) and often generalization, the expansion of fear from the CS to similar, unlearned stimuli. However, how fear learning affects early sensory processing of learned and unlearned stimuli in relation to behavioral fear responses to these stimuli remains unclear. We subjected male and female mice expressing the fluorescent calcium indicator GCaMP3 in olfactory bulb mitral and tufted cells to a classical olfactory fear conditioning paradigm. We then used awake, in vivo calcium imaging to quantify learning-induced changes in glomerular odor responses, which constitute the first site of olfactory processing in the brain. The results demonstrate that odor-shock pairing nonspecifically enhances glomerular odor representations in a learning-dependent manner and increases representational similarity between the CS and nonconditioned odors, potentially priming the system toward generalization of learned fear. Additionally, CS-specific glomerular enhancements remain even when associative learning is blocked, suggesting two separate mechanisms lead to enhanced glomerular responses following odor-shock pairings.
\end{abstract}

Key words: associative learning; calcium imaging; fear conditioning; generalization; olfactory bulb; sensory processing

\section{Significance Statement}

In the olfactory bulb $(\mathrm{OB})$, odors are uniquely coded in a spatial map that represents odor identity, making the $\mathrm{OB}$ a unique model system for investigating how learned fear alters sensory processing. Classical fear conditioning causes fear of the conditioned stimulus (CS) and of neutral stimuli, known as generalization. Combining fear conditioning with fluorescent calcium imaging of $\mathrm{OB}$ glomeruli, we found enhanced glomerular responses of the CS as well as neutral stimuli in awake mice, which mirrors fear generalization. We report that CS and neutral stimuli enhancements are, respectively, learning-independent and learning-dependent. Together, these results reveal distinct mechanisms leading to enhanced $\mathrm{OB}$ processing of fear-inducing stimuli and provide important implications for altered sensory processing in fear generalization.

\section{Introduction}

Associative fear learning, in which an organism learns that a given conditioned stimulus (CS) predicts an aversive outcome, produces behavioral fear upon subsequent encounters with that stimulus. In addition, this form of learning often generates robust generalization, the expansion of fear from the threat-predictive CS to other, unlearned stimuli (Pavlov, 1927; Pavesi et al., 2012; Resnik and

Received Dec. 19, 2017; revised March 2, 2018; accepted April 10, 2018.

Author contributions: J.M.R. and M.L.F. wrote the first draft of the paper; J.M.R. and M.L.F. edited the paper; J.M.R. and M.L.F. designed research; J.M.R. performed research; J.M.R. analyzed data; J.M.R. and M.L.F. wrote the paper.

This work was supported by the NIDCD awards R01 DC013779 to M.L.F. and F31 DC016485 to J.M.R. We thank Brittney Ross, Stephanie Staszko, and Charles Sayger for their helpful comments on the paper.

The authors declare no competing financial interests.

Correspondence should be addressed to Max L. Fletcher, Department of Anatomy and Neurobiology, University of Tennessee Health Science Center, 910 Madison Avenue, Memphis, TN 38134. E-mail: mfletch4@uthsc.edu.

DOI:10.1523/JNEUROSCI.3559-17.2018

Copyright $\odot 2018$ the authors $\quad 0270-6474 / 18 / 384623-18 \$ 15.00 / 0$
Paz, 2015). Studies in different sensory systems demonstrate that fear learning alters the neural networks responsible for encoding the CS-fear association (Bakin and Weinberger, 1990; Rogan et al., 1997; Maren, 2003a,b, 2005; Walker et al., 2005; Weinberger, 2007; Herry et al., 2008; Johansen et al., 2011; Letzkus et al., 2011; Sadrian and Wilson, 2015), but it remains unclear how representations of nonconditioned stimuli are altered, especially in relation to behavioral generalization.

The mouse olfactory system offers an excellent model in which to study such effects on sensory representations. Olfactory bulb (OB) glomeruli are the sites of synaptic contact between olfactory sensory neuron (OSN) axons and the dendrites of the OB output cells, mitral/tufted (M/T) cells (Buck and Axel, 1991). Odor-induced OSN activation generates unique spatiotemporal patterns of glomerular activity that form the initial basis of odor identity (Wachowiak and Cohen, 2001; Spors and Grinvald, 2002; Bozza et al., 2004; Mori et al., 2006; Fletcher et al., 2009; Storace and Cohen, 2017). OB imaging studies using optical indicators of neuronal 
activity expressed in OSNs (Kass et al., 2013), M/T cells (Fletcher, 2012), and inhibitory periglomerular cells (Kass and McGann, 2017) report increased responses to the trained odor following olfactory fear conditioning. Although these studies clearly indicate learning alters glomerular representations of odorants, they only investigated effects in anesthetized mice. Recent discoveries demonstrate distinct differences in odor responsivity between awake and anesthetized states in both excitatory output cells and various inhibitory interneurons (Kato et al., 2012; Blauvelt et al., 2013; Wachowiak et al., 2013).

Furthermore, other than a single recent study of inhibitory interneuron responses in anesthetized mice (Kass and McGann, 2017), little is known regarding how learning to fear the CS might affect sensory processing of neutral, unlearned odorants, especially in awake animals. Importantly in the anesthetized state, $\mathrm{M} / \mathrm{T}$ cells are more broadly tuned to odor input, leading to less efficient odor identity coding, and both inhibitory interneuron activity and centrifugal feedback are reduced in anesthetized states; each of these factors likely play an important role in learning-induced glomerular odor coding alterations. Therefore, the extent to which olfactory aversive learning modulates sensory processing of the CS as well as neutral odorants in awake mice is an important question in relation to behavioral fear generalization.

Using awake, behaving calcium imaging we report, for the first time, that a single day fear-conditioning paradigm leads to longlasting increased glomerular responses to not just the learned odor (CS) but also to other, nonconditioned odors. Such enhancements lead to increasingly overlapping glomerular representations between the conditioned and neutral odors. Furthermore, we demonstrate this global glomerular enhancement is dependent on amygdalar activation during acquisition, suggesting that global enhancements require associative fear learning. Additionally, the enhancements could not be blocked by inhibiting the amygdala during expression, meaning the enhancements occur during or shortly after learning acquisition. Together, these results indicate that classical olfactory fear learning induces changes as early as the first synapse in the olfactory system and alters glomerular odor coding in a global manner that may contribute to behavioral generalization.

\section{Materials and Methods \\ Animals}

All imaging and behavioral experiments used adult (8-14 weeks) male and female mice generated from crossing $\mathrm{FVB} / \mathrm{N}-\mathrm{Tg}$ (Thyl-cre) $1 \mathrm{Vln} / \mathrm{J}$ with B6;129S-Gt(ROSA)26Sortm38(CAG-GCaMP3)Hze/J, such that the resulting mice expressed the fluorescent calcium indicator GCaMP3 under the Thyl-promotor. Resultant mice express GCaMP3 in OB excitatory neurons, such as M/T cells. The Thyl promoter also drives expression in cortical fibers (Chen et al., 2012) and, therefore, a portion of GCaMP signal measured in the $\mathrm{OB}$ could arise from odor-evoked cortical fiber activation. However, previous work indicates axons from piriform cortex terminate sparsely in the glomerular and external plexiform layers and most densely in the $\mathrm{OB}$ granule cell layer, the deepest $\mathrm{OB}$ layer (Otazu et al., 2015). Fluorescence from such a deep or sparse signal likely contributes little to the signal measured at the glomerular surface.

Male and female mice were equally distributed between groups (i.e., $3 / 2$ in groups of 5, 2/2 in groups of 4 , etc.). Importantly, we did not notice any differences in behavioral fear expression or physiology between male and female mice. All experimental protocols were approved by the University of Tennessee Institutional Animal Care and Use Committee.

\section{General methodology}

Surgical procedures

Mice were anesthetized with ketamine/xylazine (100/10 mg/kg, i.p.) and given analgesic injections (carprofen $10 \mathrm{mg} / \mathrm{kg}$, s.c.) before surgery. Mice were secured in a custom stereotaxic apparatus (Narishige) and the bone overlying the dorsal surface of the $\mathrm{OB}$ was thinned to create a cranial window for optical imaging. Additionally, some mice were implanted with bilateral cannula in the basolateral amygdala (BLA; bregma: $-1.5 \mathrm{AP}, \pm 3.3 \mathrm{ML}$, $-5.0 \mathrm{DV})$. An anchor screw was inserted into the frontal or parietal bone and the entire skull was sealed with a thin layer of superglue (BSI). A custom-made stainless steel headbar was attached to the posterior surface of each mouse's skull for head fixation during imaging experiments. The entire skull was then covered with acrylic dental cement and mice were allowed $2 \mathrm{~d}$ to fully recover before experimentation.

\section{Drug infusions and placement verification}

Mice with BLA cannula received bilateral intracannula muscimol (MUSC; $0.5 \mu \mathrm{l}$ of $0.5 \mu \mathrm{g} / \mu \mathrm{l}$ delivered at a rate of $0.25 \mu \mathrm{l} / \mathrm{min}$ ) or an equal volume of vehicle (VEH; Ringers) infusions via a microsyringe pump. Injectors were left in place for an additional $2 \mathrm{~min}$ for diffusion. After completion of all experiments, mice with BLA cannula were perfused and brains were removed and sectioned to verify cannula placement within the BLA. Some brains were infused with Chicago Sky Blue dye (Sigma-Aldrich) before perfusion to assess possible MUSC spread. See Detailed Methodology regarding timing of drug infusions.

\section{Odorants}

An odorant panel consisting of five different odorants [ethyl valerate (E5), ethyl butyrate (E4), ethyl hexanoate (E6), benzaldehyde (BZ), 2-heptanone $(2 \mathrm{H})$ ] was used (Sigma). E5, an ethyl ester with a 5-carbon chain, was selected as the conditioned stimulus for fear conditioning following previous work in our laboratory (Pavesi et al., 2012). The other odorants were selected for their perceptual and representational similarity or dissimilarity to E5 to assess responses to chemically diverse odors. E4 and E6 were selected as structurally similar odorants, as they are also classified as ethyl esters with a 4 and 6-carbon chain, respectively. BZ, an aldehyde, and $2 \mathrm{H}$, a ketone, were selected as structurally dissimilar odorants. Importantly, all odors were known to activate glomeruli on the dorsal surface of the OB.

\section{Optical imaging}

During imaging experiments, mice were head-fixed to a custom-built treadmill (Chettih et al., 2011; Heiney et al., 2014). The treadmill allowed mice to dictate their forward/reverse motions while remaining headfixed. All mice were awake for imaging with the exception of mice in Experiment 3 (see Detailed Methodology). Imaging was performed using a Scientifica SliceScope equipped with a $4 \times$ objective (Olympus). All physiological imaging data were derived from changes in fluorescence measured from the dorsal $\mathrm{OB}$ surface, which reflects activity in the glomerular layer, likely from dendrites of M/T cells. The dorsal surface was illuminated with a LED light source centered at $480 \mathrm{~nm}$. GCaMP3 signals were bandpass filtered with a Chroma emission filter (HQ535/50) and collected using a CCD camera at $25 \mathrm{~Hz}$ (NeuroCCD-SM256, Redshirt Imaging). During imaging experiments, all mice received at least four trials of each odor used in each experiment (see Detailed Methodology) and at least four no-odor trials presented in a random order. Imaging trials lasted $5 \mathrm{~s}$ and consisted of $1 \mathrm{~s}$ of no odor, followed by a $2 \mathrm{~s}$ odor presentation, and $2 \mathrm{~s}$ no odor $($ ITI $=1-2 \mathrm{~m})$. Control no-odor trials also lasted $5 \mathrm{~s}$. All odors were delivered to the nose via a flow-dilution olfactometer. Separate flow controllers for the clean air and the pure odorant vapor mixed the flow streams at the end of the odor delivery system to achieve an approximate concentration of $0.5 \%$ saturated vapor (sv) at a flow rate of $0.7 \mathrm{~L} / \mathrm{min}$.

\section{Behavior}

\section{Olfactory fear conditioning}

All olfactory fear conditioning occurred in a standard shock chamber (Coulbourn Instruments). Mice that underwent odor-shock conditioning (Paired) received six E5-foot shock pairings (10 s E5 coterminating with an $0.8 \mathrm{~mA}, 0.5 \mathrm{~s}$ foot shock). Mice in the Shock-only condition received six unpaired foot shocks of the same intensity, whereas mice in the Odor-only condition received six E5 presentations of the same duration. Approximately $24 \mathrm{~h}$ after conditioning, mice were placed in a novel, 


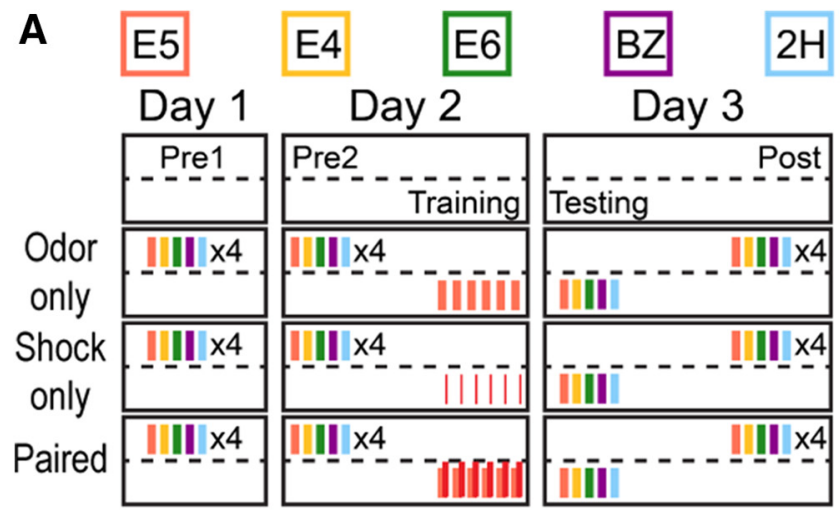

B
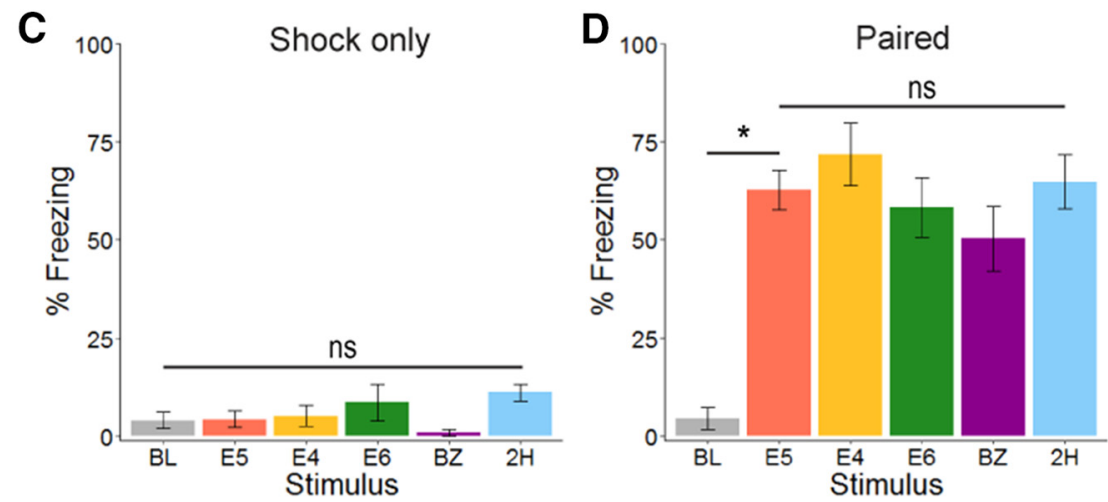

Odor only

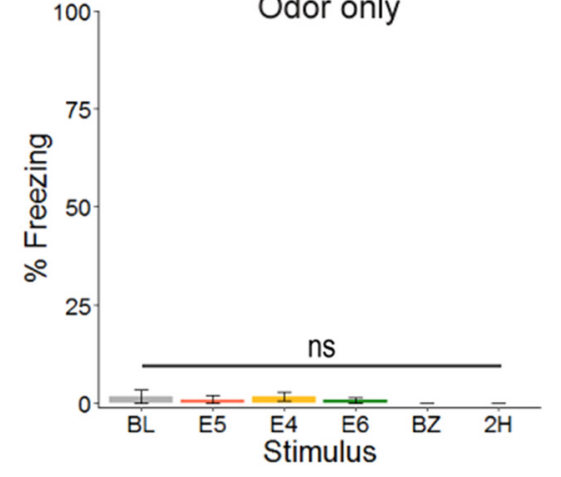

Figure 1. Olfactory aversive conditioning results in robust olfactory fear and generalization. $A$, Schematic detailing time course of experiments, the odors used (top), and paradigms for both imaging (above dotted line) and behavioral (below dotted line) experiments for each group. $\boldsymbol{B}-\boldsymbol{D}$, Twenty-four hours after training, mice were exposed to each of the five odors (E5, E4, E6, BZ, and $2 \mathrm{H}$ ) and freezing was measured. Odor-only mice $(\boldsymbol{B})$ and Shock-only mice ( $\boldsymbol{C}$ ) did not learn to fear $\mathrm{E5}$, as freezing was not significantly different from baseline ( $\mathrm{BL}$ ), and did not generalize freezing from E5 to other odors. Paired mice $(\boldsymbol{D})$ froze significantly more to $\mathrm{E} 5$ than baseline, indicating acquired fear to the $C S$. Mice generalized fear across all other tested odors (freezing to other odors not significantly different from freezing to E5). Mice freeze specifically to odor cues (E). Data presented mean $\pm S E M .{ }^{*} p<0.001$.

custom-made testing chamber. The chamber is composed of two halves separated by a perforated wall. Mice were placed in one-half of the chamber while odor delivery lines were fed through the other side, allowing odors to permeate both halves of the chamber without directly blowing on mice. The testing chamber was enclosed in an isolation chamber (Coulbourn Instruments) designed to isolate mice from all external sounds controlling odor delivery as well as any visible light. An infrared light was placed inside the testing chamber and all tests were recorded with a compatible camera. Mice were allowed a 5-10 min acclimation period in the chamber before initiation of the testing protocol, in which we assessed behavioral freezing, a widely used measure of fear, for each of the five odors used during imaging experiments. This allowed testing of specific fear to the conditioned stimulus (E5) as well as generalized fear toward neutral odors (E4, E6, BZ, and 2H) never paired with shock. Testing consisted of one $20 \mathrm{~s}$ presentation of each odor (ITI $=3 \mathrm{~min}$ ), starting in the second minute of the test session. The first 60 s of each testing session were absent of odors and were used as a baseline measure of freezing. All testing odors were intensity matched and diluted in mineral oil to achieve an approximate headspace concentration of $200 \mathrm{ppm}$. Odors were delivered to the testing chamber through dedicated lines. To ensure olfactory fearconditioned mice freeze to odor cues rather than air pressure changes or auditory cues in the testing chamber, we conditioned a small cohort of mice $(n=3)$ to E5 and tested their freezing to E5 as well as clean air delivered under the same parameters (Fig. 1E). Mice do not freeze to clean air more than baseline freezing $\left(t_{(7)}=1.472, p=0.185, r^{2}=0.236\right)$ but freeze significantly more to E5 than either clean air $\left(t_{(10)}=11.585\right.$, $\left.p<0.0001, r^{2}=0.931\right)$ or baseline freezing $\left(t_{(7)}=16.43, p<0.0001\right.$, $\left.r^{2}=0.975\right)$.

\section{Auditory fear conditioning}

During fear conditioning, Tone-shock mice $(n=3)$ were placed in the same shock chamber as olfactory fear-conditioned mice but received six tone-shock pairings ( $10 \mathrm{~s} 10 \mathrm{kHz}, 82 \mathrm{~dB}$, coterminating with an $0.8 \mathrm{~mA}$, $0.5 \mathrm{~s}$ foot shock). Twenty-four hours later they were placed in the same novel context as olfactory-conditioned mice but experienced $4-20$ s presentations of the paired tone to confirm tone-shock learning.

\section{Detailed methodology}

For convenience, each figure of a new experiment includes a schematic detailing the odorants used during imaging sessions, time course of imaging and behavioral experiments, and the training and testing paradigms used.

Experiment 1. Mice underwent 3 consecutive days of chronic awake imaging (Pre1, Pre2, and Post) to assess glomerular odor representations for each of the five odors in the odorant panel (Fig. 1A, top). Following the Pre2 imaging session, mice were split into three groups for fear conditioning: Odor only, Shock only, and Paired, and then subjected to testing as detailed above $(n=5$ each; Fig. $1 A)$. Mice experienced each of the five odors in the odorant panel during imaging and testing but only experienced E5 during training. Mice were awake for all aspects of Experiment 1.

Experiment 2. Mice $(n=4)$ underwent 2 consecutive days of chronic awake imaging (Pre1 and Pre2) before fear conditioning to E5. Approximately $72 \mathrm{~h}$ after paired conditioning, mice underwent testing and a final imaging session (Post3; see Fig. 6A). Mice were awake for all aspects of Experiment 2 and experienced each of the five odors in the odorant panel during imaging and testing. During training, mice only experienced E5.

Experiment 3. Mice $(n=3)$ underwent the exact same experimental protocol as those in Experiment 1 except that all imaging sessions (Pre1, Pre2, and Post) were completed under anesthesia (100/10 mg/kg, i.p., ketamine/xylazine). Mice were awake for all behavioral aspects of Experiment 3 (training and testing) but were anesthetized for all imaging sessions (see Fig. 7A). Mice experienced each of the five odors in the 
odorant panel during imaging and testing but only experienced E5 during training.

Experiment 4. Mice $(n=3)$ underwent 3 consecutive days of chronic awake optical imaging, but only experienced an abbreviated panel of odorants consisting of E5 and BZ during imaging sessions. The abbreviated panel was used due to the Pre-Post design of the Post imaging session (Post1 and Post2). Using all five odors would dramatically increase the length of the Post imaging session, whereas using an abbreviated panel of odors kept the Post imaging sessions at approximately the same length as all previous Post imaging sessions. Following the Pre2 imaging session, mice were subjected to auditory fear conditioning and testing. The final, postconditioning, imaging session was split into two halves (Post1 and Post2; see Fig. 8A). During Post1, we assessed baseline post-training glomerular odor representations of E5 and BZ. During Post2, each odor trial was preceded by a $10 \mathrm{~s}$ presentation of the same tone mice experienced during auditory fear conditioning to assess whether global fear states impact glomerular responses. Mice were awake for all aspects of Experiment 4. During training, mice only experienced the $10 \mathrm{kHz}, 82 \mathrm{~dB}$ conditioning tone.

Experiment 5. During surgery, these mice received bilateral BLA cannula. Mice underwent the experimental procedures outlined in Experiment 1 but received infusions of either VEH or MUSC ( $n=5$ each) 10 min before odor-shock conditioning (see Fig. 9A) to transiently inactivate the BLA during acquisition. Mice were awake for all aspects of Experiment 5. During each of the three awake imaging sessions and during testing, mice experienced all five odors in the odorant panel. During training, mice only experienced E5.

Experiment 6. During surgery, these mice received bilateral BLA cannula. Mice underwent 3 consecutive days of awake imaging, but only experienced an abbreviated odorant panel of E5, E4, and BZ during imaging. The abbreviated panel was again used due to the Pre-Post design of the final imaging session, which was split into two halves (Post1 and Post2), similar to Experiment 4 (see Fig. 10A). This time we used three odors in our abbreviated panel to assess changes to the CS (E5) as well as one structurally similar (E4) and one structurally dissimilar (BZ) odorant. In this experiment, all mice were fear conditioned to E5 and tested for fear to each of the five odors before the final imaging session. This allowed us to measure generalization to novel odorants (E6 and $2 \mathrm{H})$. Between Post1 and Post2, mice were left head-fixed on the treadmill and received infusions of either VEH or MUSC ( $n=5$ each) to transiently inactivate the BLA during expression. Ten minutes after the infusion, we resumed the Post2 imaging session half.

\section{Quantification and statistical analyses}

Physiological data collected is based on number of responsive glomeruli during the first peak respiration (a 5 frame average) following odor onset and analysis of these data were achieved by collapsing data into a single value for each glomerulus representing its mean daily response. For visual clarity, graphical representation of this same data were reduced to a single value representing the mean daily glomerular response for each odor (i.e., 5 data points per mouse per day) and presented as mean \pm SEM. Statistics were analyzed using R statistical analysis software and IBM SPSS 22.0. Equal variances were tested for all comparison data by Levene's test or Mauchley's test of sphericity, and suitable corrections were made when necessary. Parametric statistical tests including independent samples $t$ tests, ANOVAs and repeated-measures (RM) ANOVAs, and post hoc analyses were conducted when main effects were found to be significant (Dunnett's $T$ for ANOVAs and Bonferroni with adjustment for multiple comparisons for RM ANOVAs). ANOVAs were performed for all behavioral freezing and mean instantaneous frequency (MIF) data, unless otherwise noted. RM ANOVAs were performed for analyses of glomerular response data over days. $t$ Tests were performed to compare percentage change data. $N$ values for behavioral statistics represent number of individual mice, whereas $n$ values for glomerular statistics represent the number of averaged glomerular responses.

As the glomerular fluorescent signal reflects respiratory rhythm at slower respiratory rates (Spors et al., 2006; Fletcher et al., 2009; Wachowiak et al., 2013), respiratory rate analyses were conducted using the raw fluorescent traces of each imaging trial (see Fig. $3 A$ ). This method has reliably identified respiratory events compared with respiratory signal taken from a piezoelectric device wrapped around the animal's chest and by measuring intranasal pressure. Raw fluorescent traces were picked from a random glomerulus on the dorsal surface of the $\mathrm{OB}$ exhibiting distinct respiratory signal. Raw fluorescent traces were first smoothed by applying a rolling average of three frames across the entire trace. An algorithm was then used to detect each respiratory peak and to calculate the MIF. Using this method, we find respiration frequencies across a broad range $(\sim 2-6$ $\mathrm{Hz}$ ), which is in line with reported sniffing rates of head-fixed mice as measured intranasally (Shusterman et al., 2011; Blauvelt et al., 2013; McAfee et al., 2016). Independently, we have also recorded awake, headfixed sniff rates in this range during odor presentations using intranasal thermistor probes. For comparisons, odor-evoked MIF was restricted to the first four respirations after odor onset.

Spatial maps of stimulus-evoked glomerular activity were generated as previously described (Fletcher et al., 2009; Ogg et al., 2015). First, each trial was corrected for photobleaching. Then the odor-evoked change in fluorescence $(\Delta F)$ was then calculated by subtracting the average fluorescence of five frames centered around the peak of the respiration immediately preceding odor onset from five frames centered around the odor-evoked respiratory peak. Relative fluorescence change $(\Delta F / F)$ was then calculated by dividing the odor-evoked change in fluorescence $(\Delta F)$ by the average resting fluorescence gathered in the first five frames of the imaging trial. For spatial correlation analyses, the final odor map for each odor was obtained by averaging all same-odor trials within each day to generate a daily mean odor map. Using ImageJ, daily mean odor maps were aligned across odors and days for individual animals. Pseudocolored maps for individual animals are shown here as representing $\Delta F / F$ values. Next, a spatial correlation was performed using the corr 2 function in MATLAB to compare the daily mean odor map of each neutral odor to the map of E5 before (Pre2) and after (Post) training for the Paired, Odor-only, and Shock-only groups. The corr2 function produces a single Pearson's 2-D correlation coefficient for the entirety of the representative maps, including both responsive and nonresponsive regions, which allows for a holistic similarity comparison.

For quantitative analysis of individual glomerular responses, trials were first separated by odor presentation. There were a minimum of four trials for each odor on each day. Glomeruli were considered responsive if they met previously defined criteria: if the mean $\Delta F / F$ value on Prel was greater than the mean $+2 S D \Delta F / F$ value obtained from regions containing no odor-evoked activity (Fletcher, 2011; Ogg et al., 2015). The individual glomerular responses for each trial were calculated from the $\Delta F / F$ measured at the center of each defined glomerulus $(2 \times 2$ pixel average $)$. Because glomerular responses spanned a wide range from animal to animal (see Fig. 3E,F), responses were normalized to allow for pooling across subjects. Every individual responsive glomerulus was then normalized within each odor to its maximum observed $\Delta F / F$ response on Prel to that odor, such that the largest observed Prel response was equal to 1. In Experiment 1, maximum observed raw responses for each odor did not differ statistically across groups on Pre $1\left(\mathrm{E} 5: F_{(2,12)}=0.240, p=\right.$ 0.790; E4: $F_{(2,12)}=0.023, p=0.975$; E6: $F_{(2,12)}=0.268, p=0.770$; BZ: $\left.F_{(2,12)}=0.395, p=0.682 ; 2 \mathrm{H}: F_{(2,12)}=0.161, p=0.853\right)$ or Pre2 (E5: $F_{(2,12)}=0.495, p=0.621 ; \mathrm{E} 4: F_{(2,12)}=0.160, p=0.854$; E6: $F_{(2,12)}=$ $0.425, p=0.664$; BZ: $F_{(2,12)}=0.277, p=0.763 ; 2 \mathrm{H}: F_{(2,12)}=0.272, p=$ $0.766)$. A daily odor-evoked glomerular response was generated for each glomerulus by averaging all normalized same-odor trials within a single day to allow for pooling across subjects and statistical comparison of pooled glomerular responses. Averaged normalized glomerular responses on Pre1 were similar across groups (see Fig. $3 B-D$ ). Additionally, glomeruli were distinguished as E5 Responsive (i.e., glomeruli that respond to E5 alone or E5 and one or more of the other odors) or Non-E5 Responsive (i.e., glomeruli that do not respond to E5) for further analysis using the same criteria as above. Based on this classification, presentations of E5 will contain responses only from E5 Responsive glomeruli, whereas presentations of nonconditioned odors will contain responses from both E5 Responsive and Non-E5 Responsive glomeruli.

For behavioral analysis, freezing was measured from the onset of each stimulus presentation for a total of $60 \mathrm{~s}$. In Tone-Shock experiments the freezing of all four tone presentations was averaged for each mouse. 
A
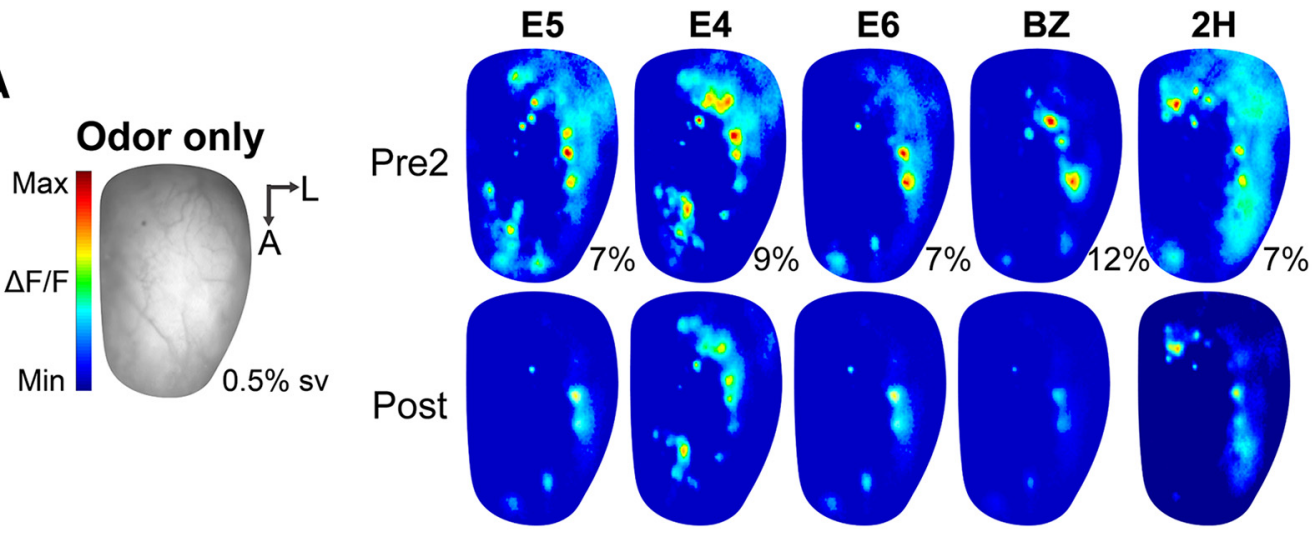

B
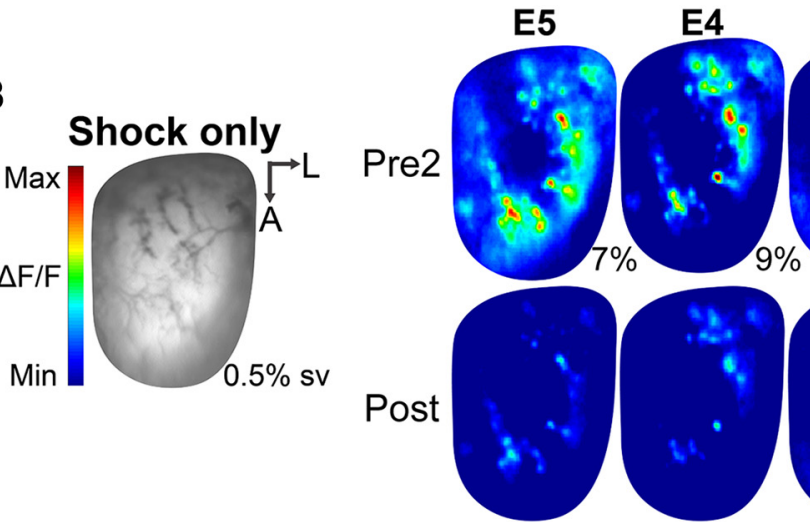

E6

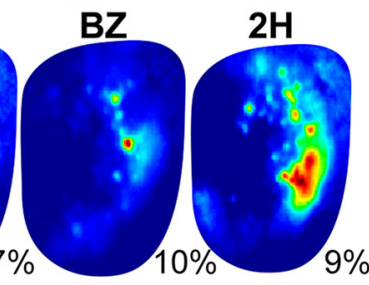

C
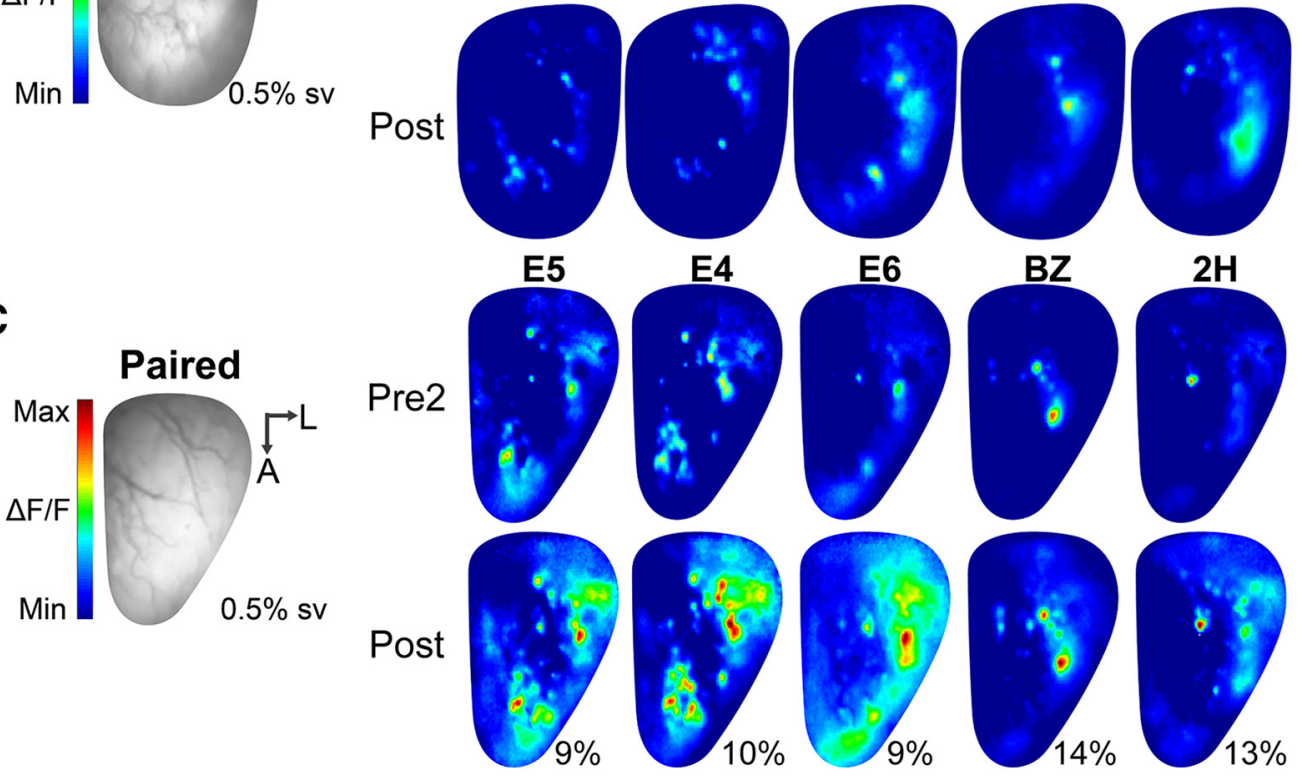

Figure 2. Olfactory aversive conditioning enhances glomerular responses. $\boldsymbol{A}-\boldsymbol{C}$, Resting light-intensity frames and pseudocolored averaged Pre2 and Post glomerular response maps from representative 0dor-only $(\boldsymbol{A})$, Shock-only $(\boldsymbol{B})$, and Paired $(\boldsymbol{C})$ mice where the pseudocolor scale is based on the day with the maximum observed responses (Pre2 for 0dor only and Shock only and Post for Paired) to avoid oversaturation of pseudocolored maps. The approximate value of the maximum observed responses $(\Delta F / F)$ used for pseudocolor scale is listed to the right of each odor. While scaling color in this manner makes Pre2 responses appear significantly weaker in the Paired group, amplitude of Pre2 responses are similar across mice for each odor. The maximum observed responses are also statistically similar across groups (see Materials and Methods).

\section{Results}

Olfactory aversive conditioning produces fear generalization to multiple odors

For Experiment 1, we began by imaging glomerular responses to the panel of odors for 2 consecutive days, establishing baseline responses (Fig. 1A). After the second imaging session, each mouse was placed into one of three training conditions: Odor only, Shock only, or Paired. Approximately $24 \mathrm{~h}$ after conditioning, mice assessed for behavioral freezing to the CS (E5) as well as neutral, unlearned odors (E4, E6, BZ, and 2H). Only mice in the Paired condition displayed strong, odor-evoked freezing $\left(F_{(5,24)}=\right.$ 12.984, $\left.p<0.0001, \eta^{2}=0.730\right)$, and only baseline freezing was significantly different from freezing to the CS $(p<0.0001)$, suggesting the Paired training paradigm produces strong fear learn- ing and broad behavioral fear generalization to all odors (Fig. $1 D)$. There was no difference in freezing for Odor-only mice $\left(F_{(5,24)}=0.635, p=0.675, \eta^{2}=0.117\right.$; Fig. $\left.1 B\right)$; or Shock-only mice across the different odors $\left(F_{(5,24)}=1.933, p=0.126, \eta^{2}=\right.$ 0.287; Fig. $1 C$ ), indicating lack of fear.

\section{Olfactory aversive conditioning potentiates glomerular} responses in awake mice

Following testing, mice underwent the final imaging session to assess the effect of conditioning on glomerular responses (Fig. $2 A-C)$. We first tested whether glomerular response amplitude changes over imaging session. Responses of Odor-only $(n=570$; $\left.F_{(1.930,1098.288)}=2636.434, p<0.0001, \eta^{2}=0.822\right)$, Shock-only $\left(n=508 ; F_{(1.895,960.989)}=2665.888, p<0.0001, \eta^{2}=0.840\right)$, and 
A
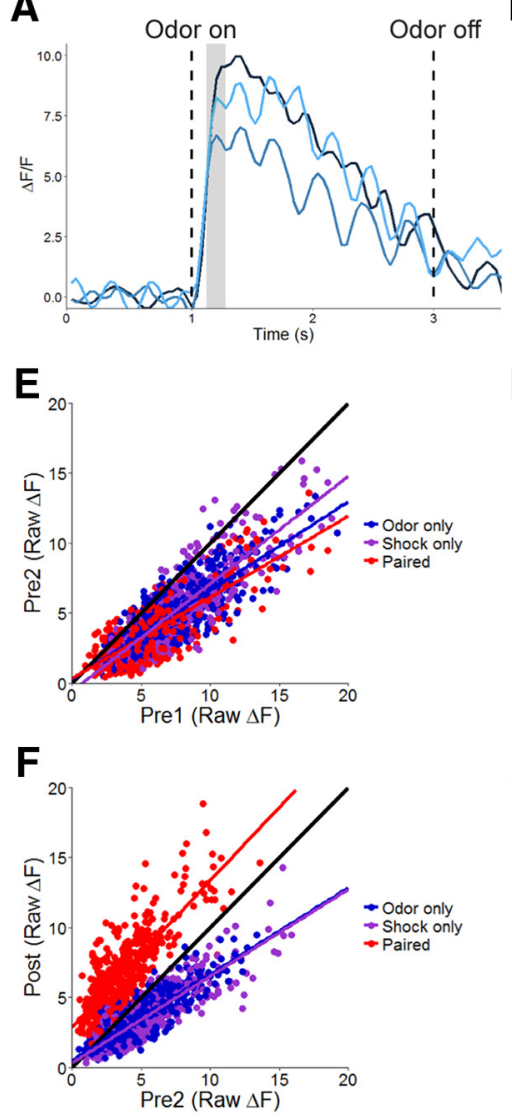

B

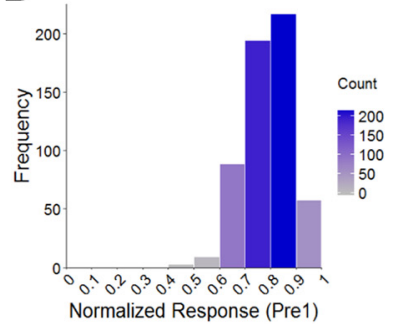

$\mathbf{E}^{\prime}$
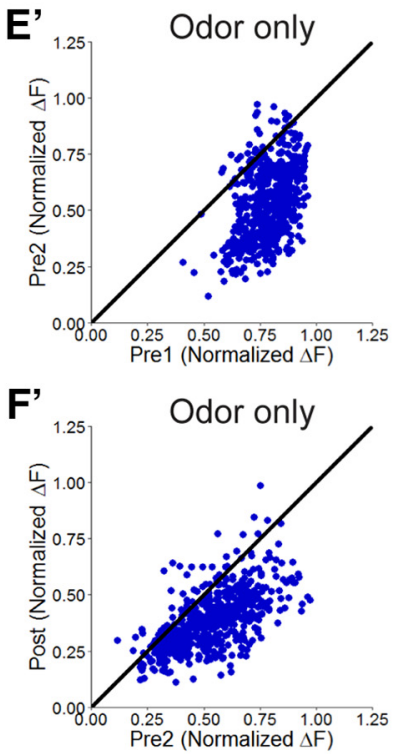

C

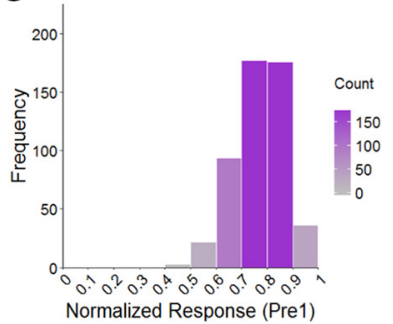

E"
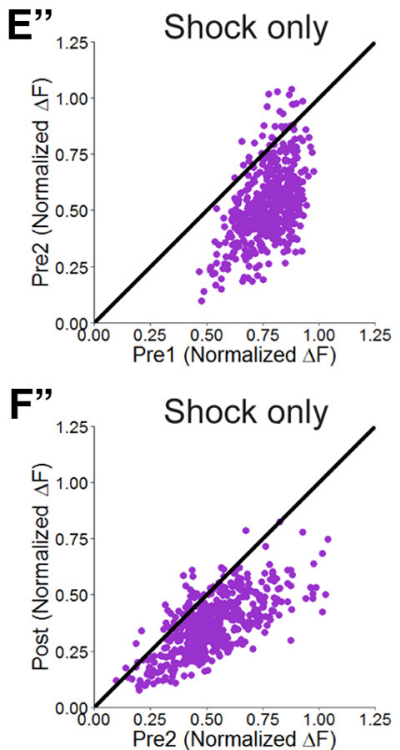

D
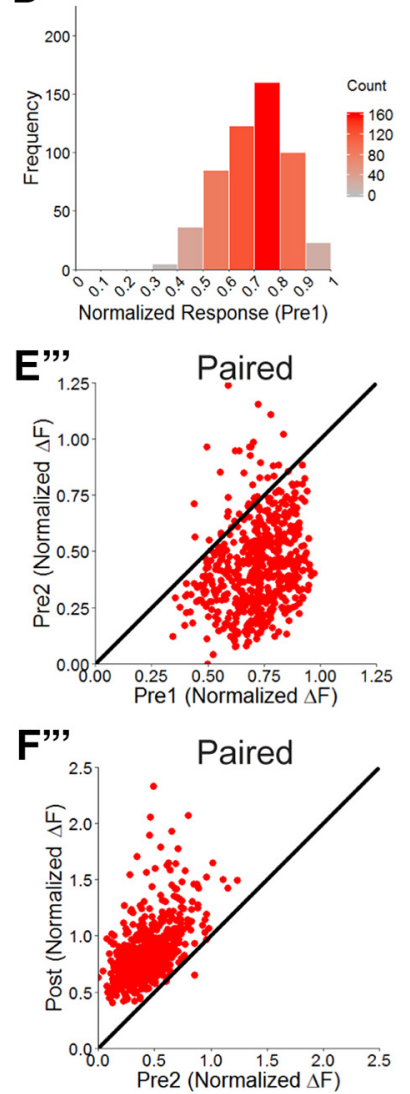

Figure 3. Post-training enhancements are independent of glomerular response amplitude. $A$, Example traces from representative glomerulus indicating Pre1 trial-to-trial variability in amplitude of response and extracted respiratory signal. Gray box illustrates five frames around the initial peak response used for analysis. $\boldsymbol{B}-\boldsymbol{D}$, Histograms of normalized Pre1 responses illustrating range and frequency of glomerular responses for 0dor-only $(\boldsymbol{B})$, Shock-only $(\boldsymbol{C})$, and Paired $(\boldsymbol{D})$ mice. Responses on Pre1 exhibit unimodal distributions with an average normalized response of $\sim 0.8$ for all groups. E, Scatterplot showing raw Pre1 ( $x$-axis) corresponding raw Pre2 ( $y$-axis) values for each recorded glomerulus from all 0dor-only (blue), Shock-only (purple), and Paired (red) mice. Raw normalized responses display similar amplitudes and experience-dependent decreases across groups. Solid black line represents theoretical "no change" line. $F$, Scatterplot showing raw Pre2 ( $x$-axis) and corresponding raw Post ( $y$-axis) values for each recorded glomerulus from all 0dor-only (blue), Shock-only (purple), and Paired (red) mice. Scatterplots of normalized responses demonstrate similar changes to those of raw responses but allow for pooling across subjects. Normalized glomerular responses generally decrease from Pre 1 to Pre2 for all groups, as evidenced by the majority of points falling below the no change line $\left(\boldsymbol{E}^{\prime}, \boldsymbol{E}^{\prime \prime}, \boldsymbol{E}^{\prime \prime \prime}\right)$. Normalized glomerular responses also generally decrease from Pre2 to Post for Odor-only $\left(\boldsymbol{F}^{\prime}\right)$ and Shock-only $\left(\boldsymbol{F}^{\prime \prime}\right)$ mice, whereas almost all glomerular responses increase from Pre2 to Post for Paired mice $\left(\boldsymbol{F}^{\prime \prime}\right)$, as evidenced by points falling above no change line. Importantly, almost all raw glomerular responses for Paired mice after training also fall above the no change line $(\boldsymbol{F}$, red). The post-training increase of raw glomerular responses appears linear, given the fit line is parallel to the no change line, indicating glomerular response enhancement is independent of glomerular response amplitude.

Paired mice $\left(n=586 ; F_{(1.743,1019.743)}=907.598, p<0.0001, \eta^{2}=\right.$ $0.608)$ changed over time. The glomerular responses of Odoronly and Shock-only mice decreased from Pre1 to Pre2 (Figs. $3 E, E^{\prime}, E^{\prime \prime}, 5 A, B$ ) and were further reduced after training (Figs. $\left.3 F, F^{\prime}, F^{\prime \prime}, 5 A, B\right)$, supporting the idea that glomerular responses decrease with increasing odor familiarity. Responses of Paired mice also decreased from Pre1 to Pre2 (Figs. $3 E, E^{\prime \prime \prime}, 5 C$ ), but were significantly enhanced after training (Fig. $3 F, F^{\prime \prime \prime}, 5 C$ ). The observed glomerular response changes were also observed in the raw, un-normalized data (Fig. 3E,F). Changes appear equal regardless of response amplitude, indicating the initial response amplitude does not impact the magnitude of experience-dependent response alterations.

Olfactory aversive conditioning does not alter sniffing rates in awake, head-fixed mice

Though mice clearly demonstrated learned fear, as measured by freezing in the testing chamber, we did not observe any overt behavioral changes on the treadmill during the Post imaging session in response to odor presentations. This is likely due to the fact that mice largely remain still on the treadmill after the first few minutes of head-fixation and it is impossible to differentiate general lack of movement from fear-induced freezing as a result of odor presentations. Although there was no overt behavioral response during imaging session, it is possible that awake mice increase their respiratory rate following training, which could alter the measured fluorescent signal (Blauvelt et al., 2013). We, therefore, examined whether altered breathing might be responsible for the observed changes reported above. MIF exhibited little to no change before and after odor onset (as measured by calculating the MIF for all respirations before odor onset and the MIF of the first four respirations after odor onset; Fig. $4 A, B, D, E, G, H)$, indicating no significant odor-evoked respiration changes in mice. Similarly, odor-evoked MIF was not significantly different between groups before or after training (Pre2: $F_{(2,73)}=2.300, p=$ 0.108 ; Post: $\left.F_{(2,73)}=0.202, p=0.817\right)$ and there was no effect of odor on odor-evoked MIF before or after training for any group (Fig. 4C, F,I). During the post-training imaging session (Post), the difference between MIF before and after odor onset was not significantly different between groups $\left(F_{(2,72)}=0.207, p=\right.$ $0.814)$. Previous work suggests that awake mice typically only modulate sniffing to novel odorants, a behavior that rapidly de- 
A
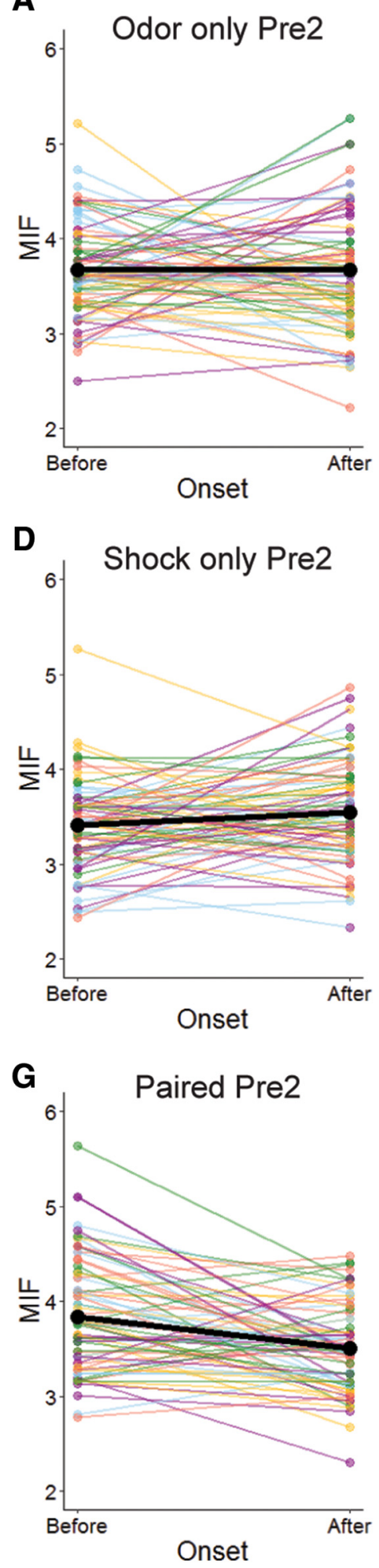

B

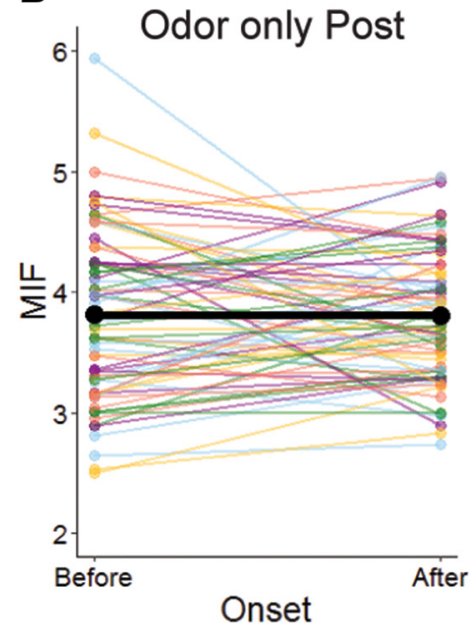

E
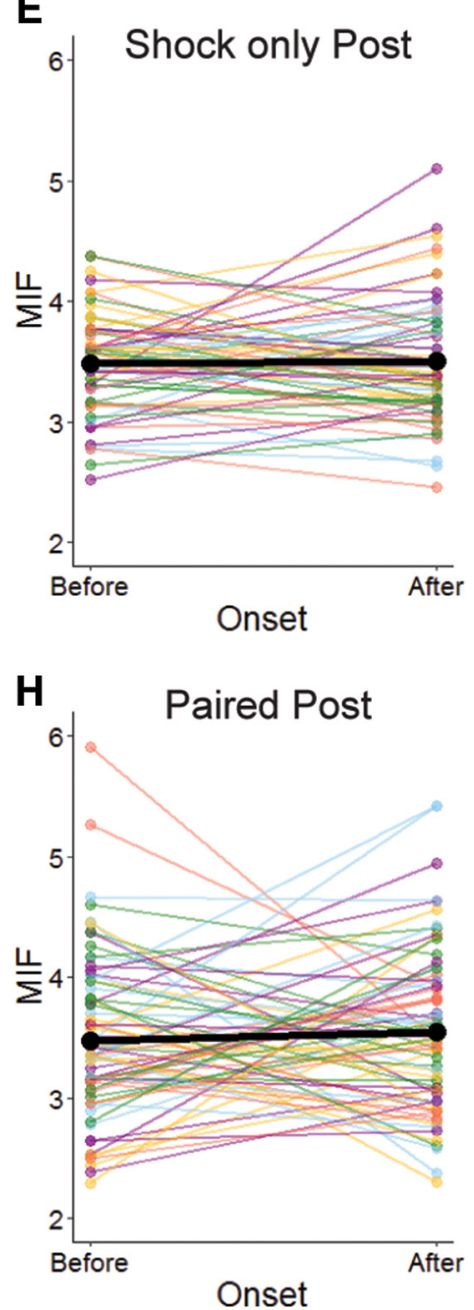
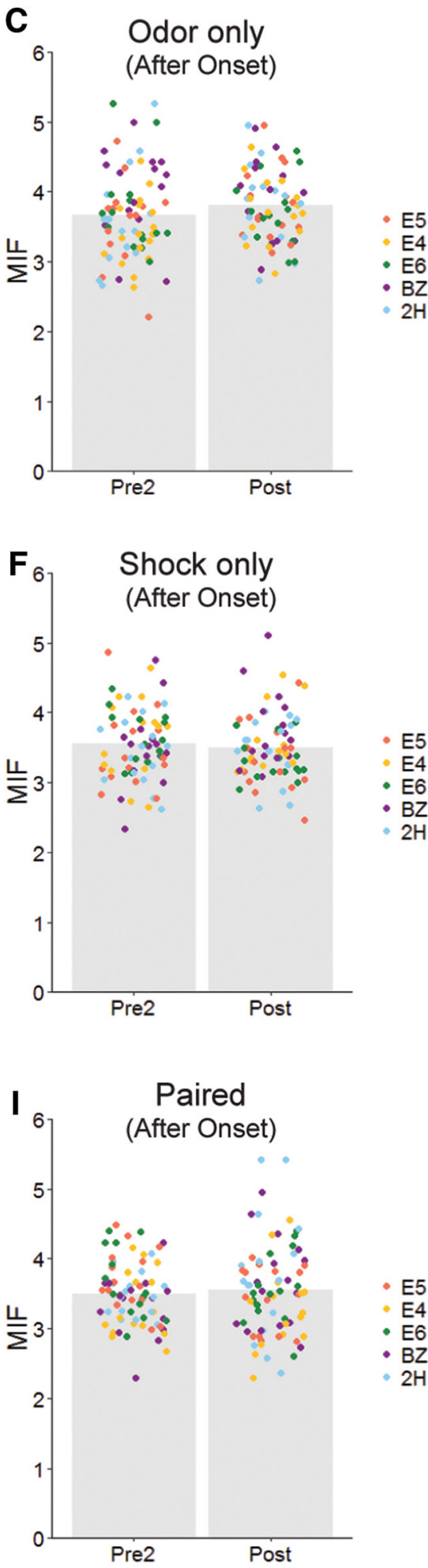

Figure 4. Mean instantaneous frequency (MIF) is stable. Extracted MIF from fluorescent trials (such as Fig. $3 A$ ) falls in line with previously published data for awake, head-fixed mice and ranges from $\sim 2-6 \mathrm{~Hz}$. Pre2 MIF is similar before and after odor onset for all 0dor-only $(\boldsymbol{A})$, Shock-only $(\boldsymbol{D})$, and Paired $(\boldsymbol{G})$ trials. Post-MIF is stable before and after odor onset for all 0dor-only $(\boldsymbol{B})$, Shock-only $(\boldsymbol{E})$, and Paired $(\boldsymbol{H})$ trials. Thick black lines represent calculated average MIF, whereas colored lines represent every trial colored by odor. Odor-evoked MIF (after odor onset) is comparable on Pre2 and Post for Odor-only $(\boldsymbol{C})$, Shock-only $(\boldsymbol{F})$, and Paired (I) mice. Importantly, MIF is not significantly higher or lower for any particular odor.

clines as odors become familiar (Verhagen et al., 2007; Wesson et al., 2008; McAfee et al., 2016). Due to the design of our imaging paradigm, all odorants become familiar within the first imaging session, therefore it is not surprising that we fail to see sniffing modulation during Pre2 or Post imaging session when odors are no longer novel. Furthermore, previous studies suggest rapid sniffing may attenuate, rather than augment, neural activity, and therefore fluorescent signal, in the OB (Verhagen et al., 2007), making in- 
A
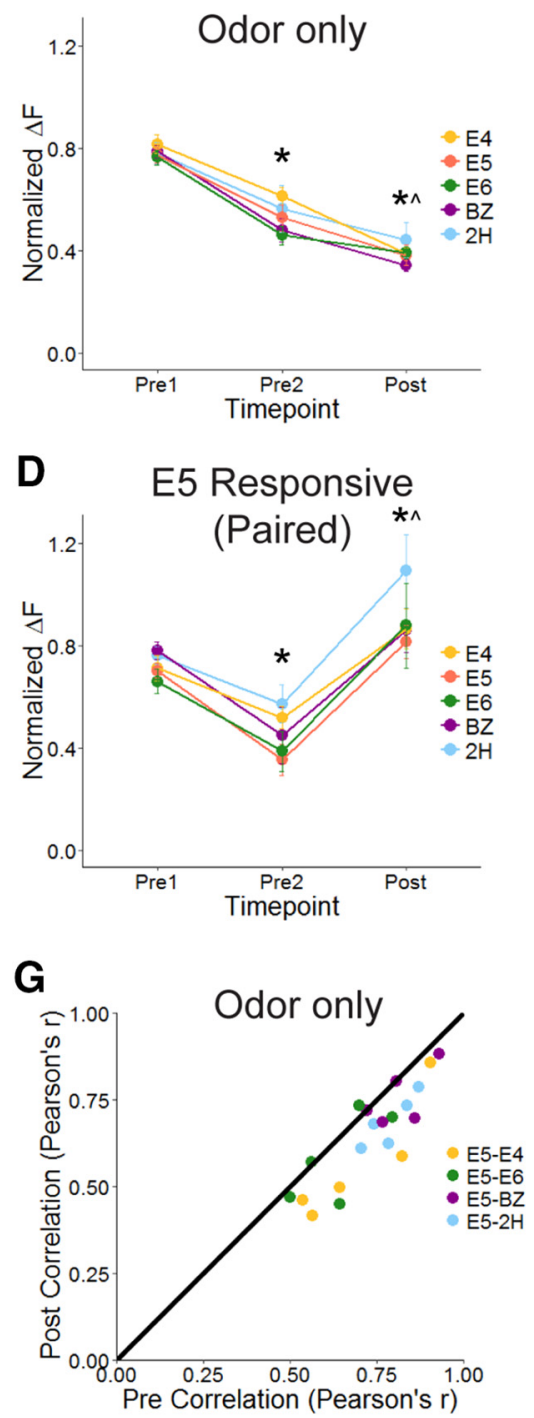

B

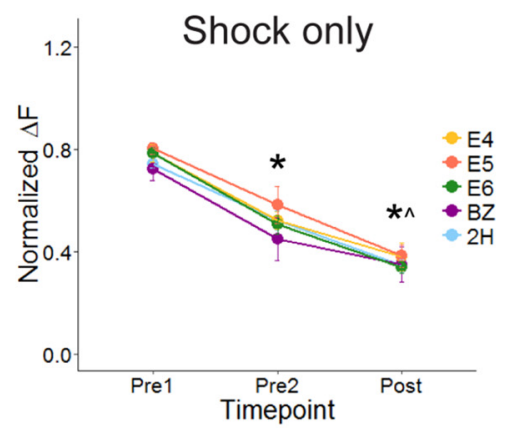

E Non E5 Responsive

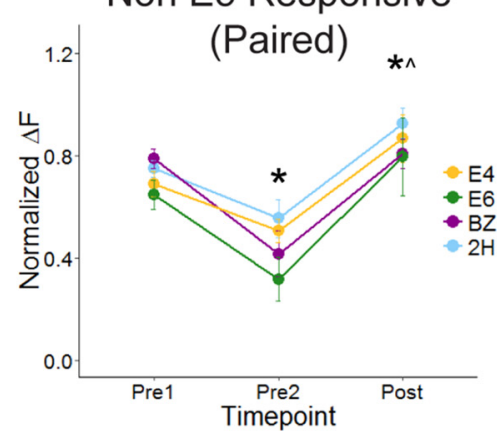

H

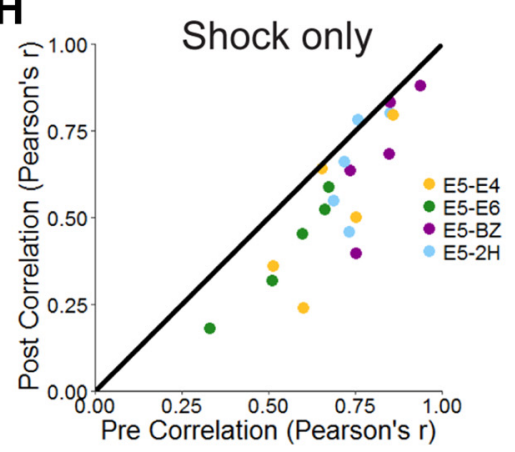

C

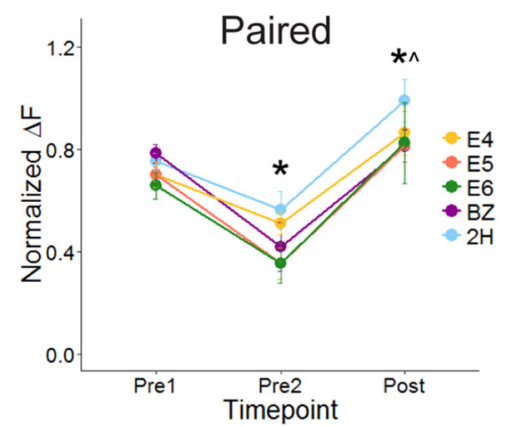

$\mathbf{F}$

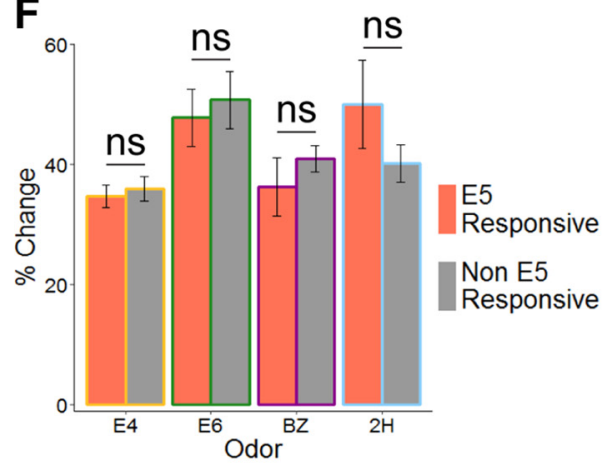

I

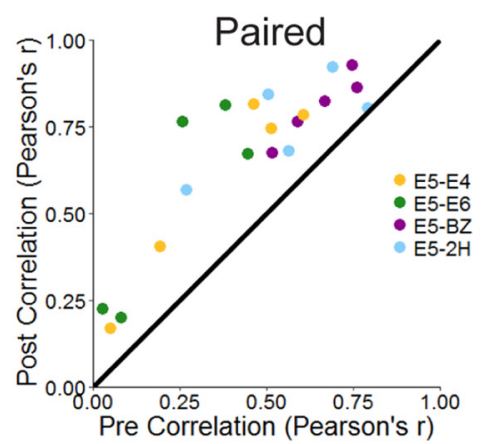

Figure 5. Enhanced responses are global, not odor- or glomerulus-specific. $A-C$, Normalized glomerular responses over time for each imaged odor. Responses for all odors continually decrease over time for 0dor-only $(\boldsymbol{A})$ and Shock-only mice $(\boldsymbol{B})$. Glomerular responses to all odors of Paired mice $(\boldsymbol{C})$ decrease before learning (from Pre1 to Pre2) followed by robust reinstatement of responses after learning (Post). The same learning-induced enhancement in Paired mice occurs in E5 Responsive (D) and Non-E5 Responsive $(\boldsymbol{E})$ glomeruli, indicating glomerular overlap does not play a significant role in learning-induced alterations $(\boldsymbol{F}) . \mathbf{G}, \boldsymbol{H}$, Scatterplots showing the average correlation of spatial glomerular activation patterns between $E 5$ and each of the neutral odors before (Pre2, $x$-axis) and after (Post, $y$-axis) for all 0dor-only $(\boldsymbol{G})$, Shock-only $(\boldsymbol{H})$, and Paired $(\boldsymbol{I})$ mice. Solid black line represents theoretical "no change" line. Activation patterns of E5 and neutral odors decorrelate after training in both 0dor-only $(\boldsymbol{G})$ and Shock-only $(\boldsymbol{H})$ mice but become more correlated after training in Paired mice $(\boldsymbol{I})$. Data presented mean \pm SEM. ${ }^{*} p<0.001$ from Pre1, $\wedge p<0.001$ from Pre2.

creased sniff rates an unlikely cause of the observed post-training glomerular response enhancement. Altogether, the lack of altered sniffing after training suggests that recorded changes in the fluorescent signals are not due to differences in respiration between groups, but reflect real changes in glomerular activity as a result of experimental condition.

\section{Olfactory aversive conditioning nonspecifically potentiates glomerular responses to all odors in awake mice}

We next examined whether the glomerular response changes were caused by a single odor by separately analyzing glomerular responses across time for each individual odor. Responses to all odors in the Odor-only group exhibited similar decreases over time (E5: $n=133$, $F_{(1.711,225.815)}=579.243, p<0.0001, \eta^{2}=0.814 ; \mathrm{E} 4: n=136, F_{(2,270)}=$ $1020.020, p<0.0001, \eta^{2}=0.883$; E6: $n=82, F_{(2,162)}=507.476, p<$ 0.0001, $\eta^{2}=0.862$; BZ: $n=118, F_{(1.597,186.899)}=1165.399, p<$
0.0001, $\eta^{2}=0.909 ; 2 \mathrm{H}: n=101, F_{(2,200)}=253.07, p<0.0001, \eta^{2}=$ $0.717)$ and responses are significantly decreased from the preceding time point for all odors (Fig. $5 A$ ). Analogous decreases across odors were observed in the responses from Shock-only mice (E5: $n=$ $120, F_{(1.637,194.820)}=531.709, p<0.0001, \eta^{2}=0.817$; E4: $n=145$, $F_{(1.880,270.737)}=771.225, p<0.0001, \eta^{2}=0.843$; E6: $n=$ $67, F_{(1.618,106.807)}=636.019, p<0.0001, \eta^{2}=0.906 ; \mathrm{BZ}: n=95$, $F_{(1.602,150.625)}=535.607, p<0.0001, \eta^{2}=0.851 ; 2 \mathrm{H}: n=81$, $\left.F_{(1.786,142.899)}=518.47, p<0.0001, \eta^{2}=0.866\right)$. Responses are significantly lower at each time point compared with the preceding session across all odors (Fig. $5 B$ ) as they are for the Odor-only group. This implies additional exposure to E5 during the Odoronly treatment or exposure to shock alone does not disproportionately affect some odors.

When exploring glomerular responses for different odors in the Paired group, we find all odors display the same pattern of decreased 
responses from Pre1 to Pre2 followed by robust potentiation at the Post time point (E5: $n=149, F_{(1.767,261.512)}=435.719, p<0.0001$, $\eta^{2}=0.746$; E4: $n=154, F_{(1.601,244.962)}=330.582, p<0.0001, \eta^{2}=$ 0.684; E6: $n=82, F_{(1.389,112.483)}=107.171, p<0.0001, \eta^{2}=$ 0.570 ; BZ: $n=106, F_{(2,210)}=208.243, p<0.0001, \eta^{2}=0.665$; $\left.2 \mathrm{H}: n=95, F_{(1.616,151.858)}=90.222, p<0.0001, \eta^{2}=0.490\right)$. Responses at Pre2 are lower than those at Pre1 for all odors and Post responses are significantly higher than those at both Pre2 for all odors (Fig. 5C). In addition, Post responses are significantly elevated above those on Pre1 for all odors except BZ, where Post and Pre1 responses are statistically equal $(p=0.346)$.

To confirm that these effects were not specific to the choice of CS odor, we trained a small number of mice to another odor in the set, BZ, and repeated the behavioral and imaging analysis. As with E5, we found similar global post-training glomerular enhancements to all odors when BZ was used as the CS. We also observed broad behavioral generalization to the other odors of the set as well as to a completely novel odorant acetophenone $\left(F_{(6,7)}=11.649, p=0.0024, \eta^{2}=0.909\right.$; freezing to BZ is significantly higher than baseline, $p=0.004$, but not significantly different between BZ and any other odor, $p<0.56$ ). Together, this suggests that the olfactory fear conditioning nonspecifically potentiates glomerular responses to all odors and leads to increased behavioral generalization, even to completely novel odors, regardless of odorant used as CS.

\section{Post-training enhancement of neutral odor responses is independent of CS overlap}

Many of the glomeruli measured were responsive to presentations of nonconditioned odors (E4, E6, BZ, and 2H) as well as to presentations of E5. Although glomerular enhancements were observed for all of the tested odors in the Paired group at the population level, it was not clear whether all glomeruli were enhanced similarly regardless of whether they responded to E5 and nonconditioned odors or only to nonconditioned odors. Therefore, we characterized each glomerulus as "E5 Responsive" or "Non-E5 Responsive" and calculated the percentage change from Pre2 to Post for each glomerulus, which allowed us to directly compare how much responses change based on whether glomeruli respond to the CS. When examining the 343 E5 Responsive glomerular responses to all different odors, only one was not enhanced after training, indicating E5 Responsive glomeruli are enhanced to all odors. Of the 243 Non-E5 Responsive glomeruli, only one was not enhanced after training, indicating Non-E5 Responsive glomeruli are also enhanced to all odors.

Although both E5 Responsive glomeruli and Non-E5 Responsive glomeruli are enhanced for all tested odors, we next wanted to know whether there was a difference in the magnitude of enhancement for nonconditioned odors between the two classifications of glomeruli. Therefore, we directly compared the percentage change from Pre2 to Post between E5 Responsive and Non-E5 Responsive glomeruli for each nonconditioned odor. There was no significant difference in the Pre 2 to Post enhancement for glomerular responses to any of the nonconditioned odors in the Paired group $\left(\mathrm{E} 4: t_{(152)}=-0.457, p=0.0648\right.$; E6: $t_{(80)}=-0.434, p=0.666$; $\left.\mathrm{BZ}: t_{(104)}=-0.943, p=0.348 ; 2 \mathrm{H}: t_{(93)}=1.358, p=0.178\right)$, signifying that the response properties of individual glomeruli responsive to $\mathrm{E} 5$ were not altered during training (Fig. $5 F$ ), thereby causing the nonspecific enhancement described above. Rather, olfactory fear learning induces a global enhancement of all glomeruli, independent of odorant and overlap with the CS.

\section{Olfactory fear conditioning increases odor representation} similarity between CS and neutral odors

We next investigated whether the changes in individual glomerular responses following training altered the overall representation of nonconditioned odors (E4, E6, BZ, and $2 \mathrm{H}$ ) to be more or less similar to the conditioned odor (E5). To accomplish this, we generated the averaged glomerular response maps of each odor and asked how well correlated the spatial pattern of activation was between each of the nonconditioned odors and E5 before and after training. Our analysis suggests that nonconditioned odors are equally as correlated or modestly decorrelated with E5 after training for both Odor-only (correlation values decreased an average of 0.0875 ) and Shock-only mice (correlation values decreased an average of 0.1387 ; Figs. $5 G, 3 H$ ). In contrast, the patterns of spatial activity in response to nonconditioned odors are more similar to the response elicited by presentations of the CS after training for Paired mice than before (correlation values increased an average of 0.2153 ; Fig. 5I).

\section{Olfactory fear learning induces long-lasting behavioral fear and enhanced glomerular responses}

In Experiment 2 we evaluated the duration of the post-learning effects. We repeated the Paired condition of the previous experiment but tested and imaged $72 \mathrm{~h}$, rather than $24 \mathrm{~h}$, after footshock training (Fig. 6A). Mice exhibited robust freezing $72 \mathrm{~h}$ after training $\left(F_{(5,18)}=6.677, p=0.001, \eta^{2}=0.650\right)$, where only baseline freezing was significantly different from freezing to the CS (E5), $p<0.0009$. This indicates the odor-shock training paradigm produces broad, long lasting fear generalization across all odors (Fig. 6B).

The same mice also underwent awake imaging $72 \mathrm{~h}$ after training (Post3) to characterize whether learning-induced glomerular enhancements were also long lasting. Again, global glomerular responses changed over time $\left(n=401 ; F_{(1.529,611.410)}=941.730\right.$, $\left.p<0.0001, \eta^{2}=0.702\right)$. These mice displayed the characteristic response decrease from Pre1 and Pre2 and an enhancement of glomerular responses following training that was still visible $72 \mathrm{~h}$ later (Post3). Once again, this pattern is not driven by any particular odor $\left(\mathrm{E} 5: n=107, F_{(1.642,174.104)}=230.484, p<0.0001, \eta^{2}=0.685\right.$; E4: $F_{(1.542,161.995)}=222.538, p<0.0001, \eta^{2}=0.679 ;$ E6: $F_{(1.547,94.374)}=202.332, p<0.0001, \eta^{2}=0.768 ; \mathrm{BZ}: F_{(1.705,78.445)}=$ 284.862, $p<0.0001, \eta^{2}=0.861 ; 2 \mathrm{H}: F_{(1.310,102.161)}=225.059$, $\left.p<0.0001, \eta^{2}=0.743\right)$. In fact, responses to each odor on Post3 were significantly higher than responses for the same odor on Pre2 (Fig. 6C; $p<0.001$ ). Much like the initial enhancement, the sustained enhancement is not odor specific, indicating that olfactory fear learning globally increases glomerular responses in a long-lasting manner.

\section{Anesthetized mice display weaker glomerular enhancements and suppression following olfactory fear learning}

In Experiment 3, we examined whether wakefulness modulates the olfactory learning-induced glomerular response profile. We repeated the Paired conditioning as in the first set of experiments but completed each of the imaging sessions in anesthetized, rather than awake, mice (Fig. 7A). We confirmed olfactory fear learning in these mice by testing their awake behavioral freezing to each of the odors $24 \mathrm{~h}$ following odor-shock conditioning (Fig. 7B; $\left.F_{(5,18)}=3.224, p=0.030, \eta^{2}=0.472\right)$. Only freezing during the baseline minute is significantly different from freezing to E5 ( $p=$ $0.007)$, suggesting broad behavioral generalization similar to the above experiments even following repeated administration of anesthetics. 
Mice in the anesthetized condition also display decreased glomerular responses from Pre1 to Pre2 (Fig. 7B,C) followed by learning-induced glomerular enhancements $\left(n=292 ; F_{(1.496,435.357)}=68.702\right.$, $\left.p<0.0001, \eta^{2}=0.191\right)$; however, we noted the enhancement appeared reduced compared with the awake Paired group. A scatterplot demonstrated suppression of several glomeruli after training (Fig. $7 E$ ), which occurred in all odors (E5: $n=75$, $F_{(1.492,110.435)}=24.124, p<0.0001, \eta^{2}=$ 0.246; E4: $n=80, F_{(1.315,103.906)}=22.307$, $p<0.0001, \eta^{2}=0.220$; E6: $n=58$, $F_{(1.297,73.934)}=11.469, p<0.0005, \eta^{2}=$ 0.168; BZ: $n=24, F_{(2,46)}=6.241, p<$ $0.004, \quad \eta^{2}=0.213 ; 2 \mathrm{H}: n=55$, $F_{(1.409,76.098)}=12.232, p<0.0002, \eta^{2}=$ $0.185)$. In addition, glomerular responses to both E6 and BZ were not significantly different from Pre 2 to Post $(p=0.135$ and 0.231 , respectively). Of the 292 glomeruli analyzed in the anesthetized mice, only 59.9\% (175 total; E5 = 47, E4 = 56, E6 = $34, \mathrm{BZ}=13,2 \mathrm{H}=25)$ were enhanced after training and 40.1\% (117 total; E5 = $28, \mathrm{E} 4=24, \mathrm{E} 6=24, \mathrm{BZ}=11,2 \mathrm{H}=30$ ) were decreased. Comparatively, in the awake Paired condition only 2 of the 586 glomeruli $(0.34 \%)$ analyzed exhibited lower responses after training. Also of note, we observed a smaller decrease in glomerular responses from Pre1 to Pre2 in anesthetized mice than in awake mice, which supports previous work (Kato et al., 2012). This illustrates wakefulness modulates both passive experience- and learning-induced glomerular alterations and that anesthetized imaging in the context of experience-dependent glomerular transformations does not necessarily mirror that seen in an awake condition.

\section{Post-training glomerular response enhancements are independent of general fear states}

One possible explanation for post-training glomerular response alterations in awake mice that differ from those observed in anesthetized mice is that the imaging paradigm requires continually presenting fear-inducing stimuli to the mice to assess post-training changes. It is possible that this repeated exposure induces a general fear state that enhances glomerular responses. Therefore, in Experiment 4 we devised a paradigm to image glomerular responses to odors in the presence and absence of a fear inducing stimulus (Fig. 8A). Instead of fear conditioning Paired mice to an odor, we conditioned them to a $10 \mathrm{kHz}, 82 \mathrm{~dB}$ tone. Additionally, we split the Post time point into two halves (Post1 and Post2). In the first half (Post1), we imaged odor responses normally; however, in the second half (Post2), we imaged odor responses immediately after a 10 s presentation of the conditioned tone.

Tone-shock conditioning produced robust freezing to presentations of the conditioned tone relative to baseline freezing in the first minute (Fig. $8 B ; n=3, t_{(4)}=-6.650, p<0.003$ ). Glomerular responses significantly decreased across imaging sessions (Fig. $8 C$; $\left.n=128 ; F_{(2.317,294.304)}=729.000, p<0.0001, \eta^{2}=0.852\right)$ and the decrease was consistent across the two tested odors (E5: $n=72$, $F_{(2.215,157.276)}=544.812, p<0.0001, \eta^{2}=0.885$; BZ: $n=56$,
$\left.F_{(1.792,98.583)}=239.018, p<0.0001, \eta^{2}=0.812\right)$. All time points are significantly different from one another except Post 1 and Post2 ( $p=1.000$, for both odors). The lack of significant difference between recorded responses at Post1 (in absence of fearinducing tone) and Post2 (in presence of fear-inducing tone) suggests a global fear state is not responsible for the augmented responses observed in odor-shock conditioned mice, but that the enhancement is likely due to fear learning itself.

\section{Global, but not CS-specific, glomerular enhancements are fear learning dependent}

Because the post-training enhancements could not be attributed to a global fear state that might simply strengthen all incoming sensory information, we next evaluated whether glomerular enhancements were dependent upon olfactory fear learning. In Experiment 5, we infused MUSC into the BLA (see Fig. 10B) $10 \mathrm{~min}$ before odor-shock training to inactivate the BLA, thus interrupting fear learning (Fig. 9A). Mice that received infusions of VEH immediately before training demonstrate typical fear learning (Fig. 9B; $n=5, F_{(5,24)}=8.703, p<0.0001, \eta^{2}=0.645$ ). Mice freeze significantly more to E5 than baseline $(p<0.001)$ and generalize fear from $\mathrm{E} 5$ to $\mathrm{E} 4, \mathrm{E} 6$, and $2 \mathrm{H}$, but not to $\mathrm{BZ}$ ( $p=$ 0.020 , all others not significantly different from E5). On the other hand, MUSC mice did acquire learned fear (Fig. $9 C ; n=5, F_{(5,24)}=$ 1.107, $p=0.383, \eta^{2}=0.187$ ), confirming that infusions of MUSC into the BLA before training effectively block olfactory fear learning.

Not surprisingly, glomerular responses of VEH mice differed over the imaging sessions $\left(n=596 ; F_{(1.384,823.392)}=754.435, p<\right.$ $\left.0.0001, \eta^{2}=0.559\right)$, with a significant decrease in responses from Pre1 to Pre 2 and a significant increase from Pre2 to Post (Fig. 

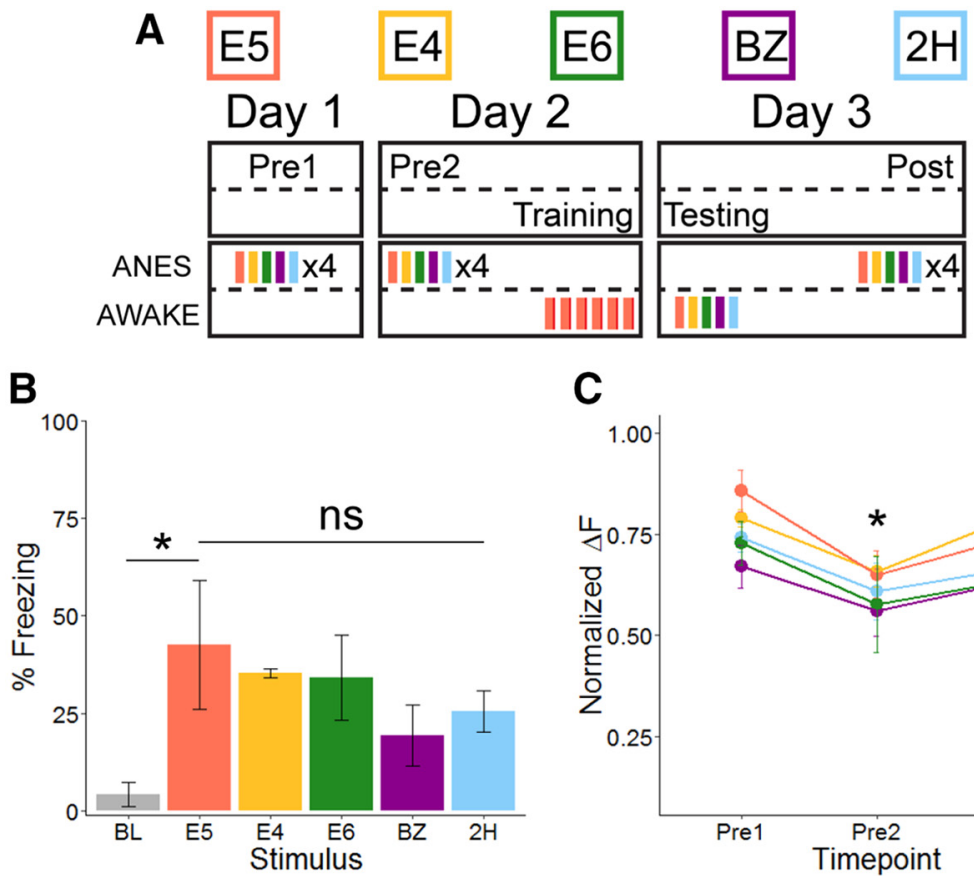

\section{C}
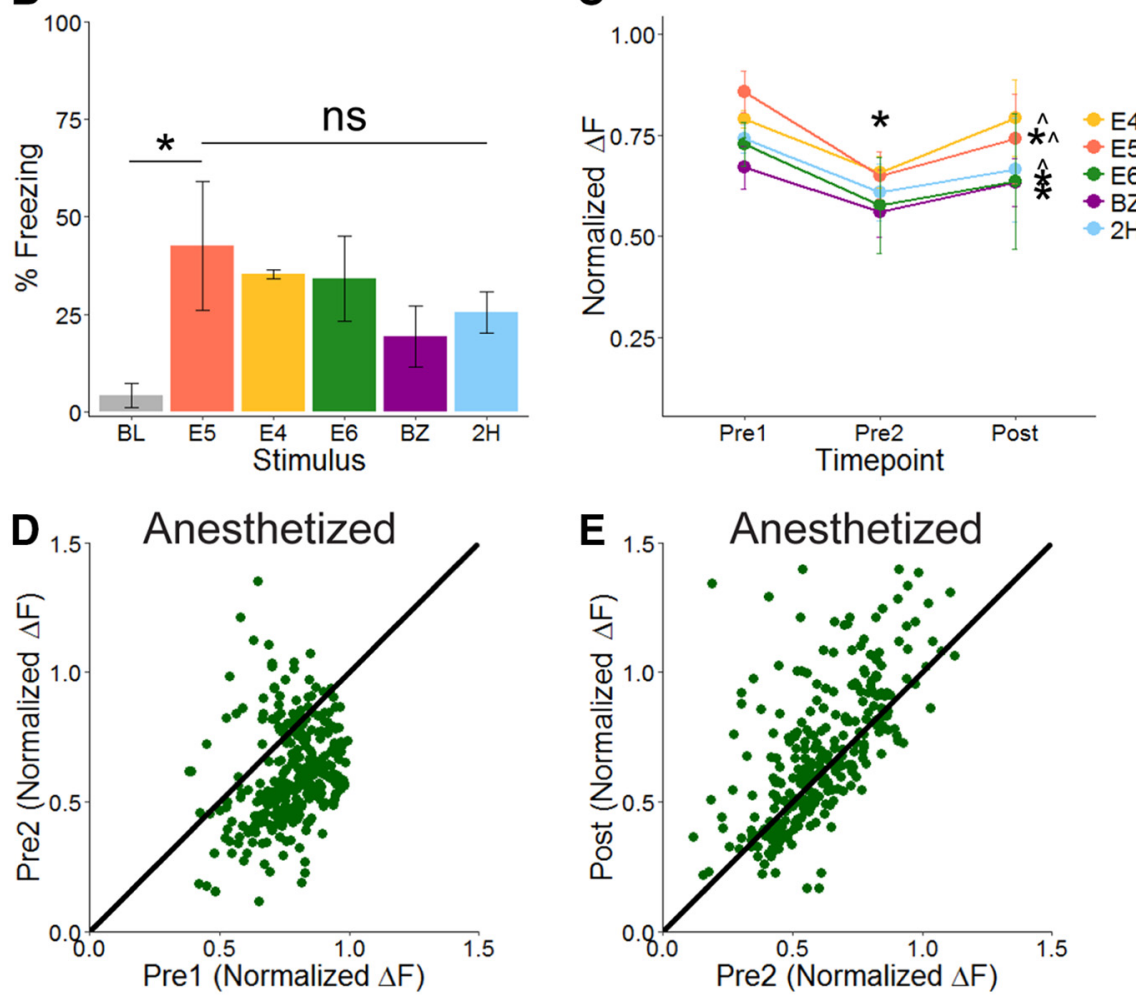

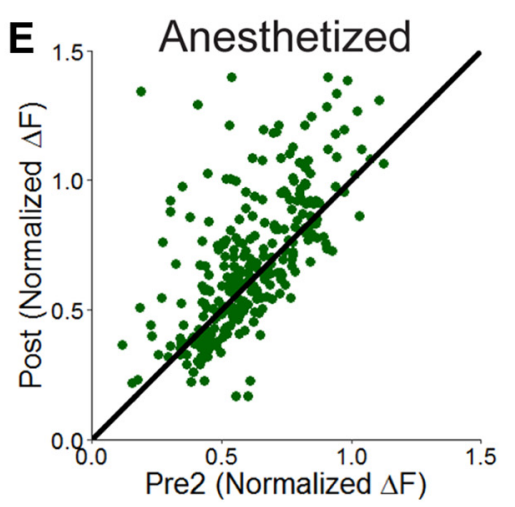

Figure 7. Learning-induced glomerular changes are variable in anesthetized mice. $\boldsymbol{A}$, Schematic detailing time course of experiments, the odors used (top), and paradigms for both imaging (above dotted line) and behavioral (below dotted line) experiments. In this experiment mice are anesthetized (ANES) for all imaging sessions but awake during behavioral assays. $\boldsymbol{B}$, Twenty-four hours after training, mice froze significantly more to $\mathrm{E} 5$ than baseline, indicating acquired fear and generalized fear across all other tested odors (freezing to other odors not significantly different from freezing to $\mathrm{E} 5$ ). ${ }^{*} p<0.05$. C, Glomerular responses of anesthetized mice decreased from Pre1 to Pre2. After training (Post), only averaged responses of E5, E4, and 2H were significantly enhanced (relative to Pre2), whereas responses to E6 and BZ were not significantly different. D, E, Scatterplots showing normalized Pre1 ( $x$-axis)/Pre2 $(y$-axis) responses $(\boldsymbol{D})$ or Pre2 $(x$-axis)/Post $(y$-axis) responses $(\boldsymbol{E})$ for each recorded glomerulus from anesthetized mice. Solid black line represents theoretical "no change" line. Glomerular responses generally decrease from Pre1 to Pre2, as evidenced by the majority of the points falling below the no change line (D). On average, responses slightly increase from Pre2 to Post (E); however, of the 292 glomeruli analyzed in the anesthetized mice, only $59.9 \%$ were enhanced after training, whereas $40.1 \%$ were suppressed. Data presented mean \pm SEM. ${ }^{*} p<0.001$ from Pre1, $\wedge p<0.001$ from Pre2.

$9 D, F)$, similar to that of noncannulated Paired mice. In general, glomerular responses of MUSC mice changed over time $(n=$ $\left.612 ; F_{(1.767,1079.568)}=599.623, p<0.0001, \eta^{2}=0.495\right)$ and responses decreased from Pre1 to Pre2 with an additional, statistically significant decrease from Pre2 to Post (Fig. 9E, G; $p<0.001$ ). The lack of post-training enhancement in the MUSC group suggests these changes are learning-dependent; however, we noticed not all glomerular responses in the MUSC group were further decreased following odor-shock training. To determine whether responses to individual odors were differentially affected after training with infusions, we analyzed the responses of each odor individually.

In the VEH group, all odors presented similar patterns of responsivity over the imaging sessions (E5: $n=140, F_{(1.628,226.249)}=$
393.528, $p<0.0001, \eta^{2}=0.739 ; \mathrm{E} 4: n=$ $141, F_{(1.335,186.900)}=190.665, p<0.0001$, $\eta^{2}=0.577$; E6: $n=91, F_{(1.369,123.206)}=$ 119.941, $p<0.0001, \eta^{2}=0.571 ; \mathrm{BZ}: n=$ 99, $F_{(1.206,118.164)}=98.089, p<0.0001$, $\eta^{2}=0.500 ; 2 \mathrm{H}: n=125, F_{(1.654,205.090)}=$ 209.034, $\left.p<0.0001, \eta^{2}=0.628\right)$ with significantly lower Pre2 responses than Pre1, and significantly higher Post than Pre2 responses for all five odors (Fig. 9F; $p<0.001)$. In contrast, not all odor responses in MUSC mice continue to decrease after training $\left(\mathrm{E} 5: n=160, F_{(1.622,257.85)}=\right.$ 195.242, $p<0.0001, \eta^{2}=0.551 ; \mathrm{E} 4: n=$ $156, F_{(1.543,239.236)}=284.548, p<0.0001$, $\eta^{2}=0.647$; E6: $n=89, F_{(1.788,157.361)}=$ 234.108, $p<0.0001, \eta^{2}=0.727$; BZ: $n=85$, $F_{(2,168)}=179.119, p<0.0001, \eta^{2}=$ $0.681 ; 2 \mathrm{H}: n=122, F_{(2,242)}=579.7, p<$ $\left.0.0001, \eta^{2}=0.827\right)$. Although responses to all odors decrease from Pre1 to Pre2 ( $p<0.001$ for all 5 odors) at the population level, only glomerular responses to nonconditioned odors (E4, E6, BZ, and $2 \mathrm{H})$ display further suppression from Pre2 to Post (Fig. 9G; $p<0.001$ ), whereas glomerular responses to the conditioned odor, E5, are enhanced after odor-shock training $(p<0.001)$. In fact, Post responses to E5 are not significantly different from those measured on Prel ( $p=$ 0.14 ), indicating full reinstatement of the initial E5 response after fear conditioning even in the absence of fear learning. These results illustrate that generalized, or global, glomerular enhancement is learning-dependent, whereas CS-specific enhancements do not require learning.

Again, many glomeruli responsive to E5 are also responsive to presentations of the other, nonconditioned odors. Further, responses to E5 were the only ones enhanced after training in MUSC mice. Therefore, we wanted to explore whether all E5 Responsive glomeruli might be enhanced, even when responding to neutral odors, but the effect obscured by averaging the responses of E5 Responsive with "Non-E5 Responsive" glomeruli. We directly compared the effects of E5 overlap as conducted for Experiment 1. When mice received VEH infusions before odor-shock training, E5 glomerular responses increased $31.364 \pm 1.500 \%$ from Pre 2 to Post. Glomerular overlap with E5 appeared to have no effect on the amount of observed post-training change for most of the nonconditioned odors (Fig. 9H; E4: $\mathrm{t}_{139}=0.591, p=0.555 ; \mathrm{E} 6: \mathrm{t}_{89}=-1.895, p=0.061$; BZ: $\left.\mathrm{t}_{97}=-2.428, p=0.017 ; 2 \mathrm{H}: \mathrm{t}_{123}=1.046, p=0.298\right)$ with only BZ exhibiting a significant difference between E5 Responsive and Non-E5 Responsive in terms of percentage change. E5 glomeruli of MUSC mice increased their responses $23.139 \pm 1.492 \%$ after training, whereas responses to all other odors decreased. Glomerular overlap with E5 did not impact the change from Pre2 to Post for any of the nonconditioned odors (Fig. 9I; E4: $t_{(154)}=-0.153$, 
$p=0.879 ; \mathrm{E} 6: \mathrm{t}_{(85.762)}=0.797, p=0.428$; $\mathrm{BZ}: t_{(83)}=-1.537, p=0.128 ; 2 \mathrm{H}: t_{(120)}=$ $-0.047, p=0.963)$. This suggests a mechanism for odor rather than glomerulusspecific modulation in the OB following odor-shock training, even in the absence of fear learning (Fig. 9J). Together, the results of this experiment provide evidence for two separate mechanisms that modulate $\mathrm{OB}$ glomerular responses. One is specific to the CS and does not require learning to regulate responses, whereas the second is learning-dependent and results in a global, or nonspecific, gain across OB glomeruli.

\section{Suppressing fear centers during expression does not suppress learning-induced glomerular enhancements}

Finally, in Experiment 6, we explored whether the global post-training glomerular enhancements could simply be due to amygdalar activation as a result of a fear state that increased sensory information in a modality-specific manner. Therefore, we investigated the effect of amygdalar inactivation on post-learning glomerular responses by infusing MUSC into the BLA (Fig. 10B) halfway through the Post imaging session. This allowed for direct comparison of odor responses while the BLA was normally active or inactivated, respectively (Fig. 10A). Both groups of mice were subjected to odor-shock training, resulting in significant behavioral freezing (Fig. 10C,D; VEH: $n=5, F_{(5,24)}=9.056$, $p<0.0001, \eta^{2}=0.654$; MUSC: $n=5$, $\left.F_{(5,24)}=17.437, p<0.0001, \eta^{2}=0.784\right)$. Mice exhibit significantly higher freezing to E5 than baseline $(p<0.001$, both groups), with broad generalization from E5 to all other odors in VEH mice $(p>0.065)$ and generalization from E5 to all odors except BZ $(p<0.001)$ in MUSC mice. These behavioral results are similar to the $\mathrm{VEH}$ results obtained in the previous experiment, which also contained mice that had bilateral cannula implantation in the BLA. Importantly, mice generalized fear from E5 to both E6 and 2H even though these are novel odors never experienced during previous imaging sessions (Fig. 10C,D). This is similar to earlier experiments where mice trained to BZ generalizing to the novel odorant acetophenone. Therefore, mice broadly generalized fear after odor-shock conditioning, even to the novel odorants $\mathrm{E} 6$ and $2 \mathrm{H}$.

Glomerular responses of VEH mice changed over time $(n=$ $\left.367 ; F_{(1.477,540.494)}=224.211, p<0.0001, \eta^{2}=0.380\right)$, demonstrating a significant decrease in responses from Pre1 to Pre2 $(p<0.001)$, rebound of glomerular responses from Pre 2 to Post 1 $(p<0.001)$, and a small decrease from Post 1 to Post 2 , after VEH infusion into the BLA. Glomerular responses of MUSC mice changed similarly over the imaging sessions $\left(n=379 ; F_{(2.151,813.016)}=\right.$ 879.834, $\left.p<0.0001, \eta^{2}=0.700\right)$, and display a significant suppression of responses from Pre1 to Post2 $(p<0.001)$, enhancement from Pre 2 to Post $1(p<0.001)$ and a significant decrease from Post 1 to Post2 $(p=0.002)$ after MUSC infusion. We no- ticed that all odors for both groups follow the same trend of decreasing from Pre1 to Pre2, with a rebound of the response from Pre2 to Post1, but that individual odors exhibit mixed response alterations between Post1 and Post2. Therefore, we analyzed each odor separately over time (VEH E5: $n=139, F_{(1.359,187.490)}=144.905$, $p<0.0001, \eta^{2}=0.512$; E4: $n=142, F_{(2.212,311.887)}=252.805, p<$ 0.0001, $\eta^{2}=0.642$; BZ: $n=86, F_{(1.291,109.740)}=19.612, p<0.0001$, $\eta^{2}=0.187$; MUSC E5: $n=145, F_{(1.980,285.160)}=307.731, p<$ 0.0001, $\eta^{2}=0.681$; E4: $n=145, F_{(2.478,356.836)}=494.151, p<$ $0.0001, \eta^{2}=0.774$; BZ: $n=89, F_{(1.689,148.633)}=145.011, p<0.0001$, $\left.\eta^{2}=0.622\right)$. In doing so, we discovered that responses to E5 and E4 were significantly decreased ( $p<0.001$ and 0.02 , respectively), but BZ responses were not significantly different $(p=0.116)$ from Post1 to Post2 in mice receiving VEH infusions (Fig. 10E). In mice receiving MUSC infusions, responses to E5 and E4 were not significantly different ( $p=1.000$ and 0.126 , respectively), but BZ responses were significantly decreased $(p<0.001)$ from Post1 to Post2 (Fig. 10F).

In light of the mixed-response profiles from Post 1 to Post 2 in both groups, we decided to test whether the response changes between these imaging session halves was dependent upon experimental condition (infusion of either VEH or MUSC between the two halves). To do so, we calculated the percentage change for each glomerulus from Post1 to Post2. The response decrease from Post 1 to Post 2 was not significantly different between 
A

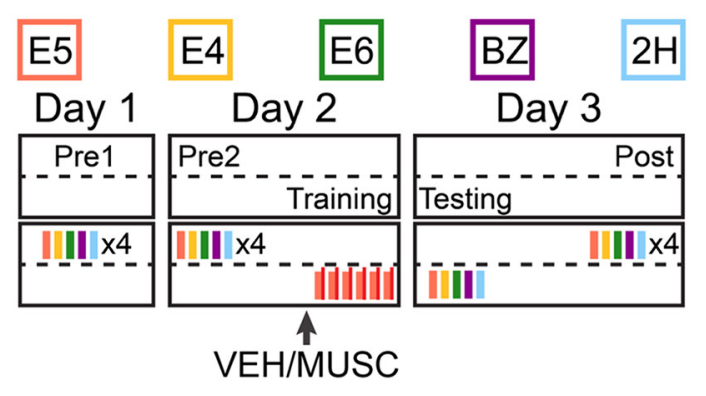

B

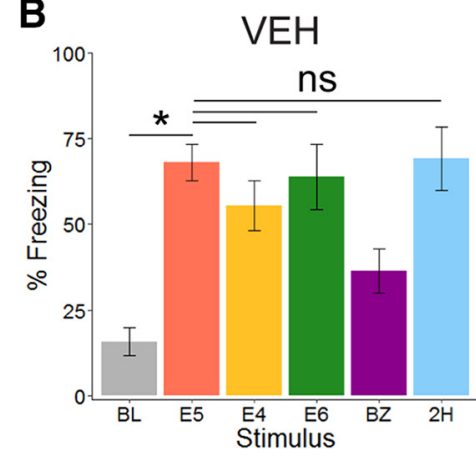

C

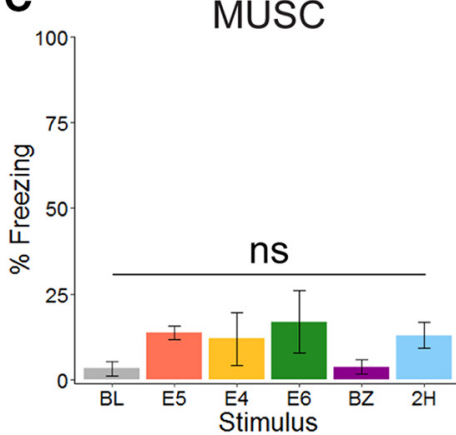

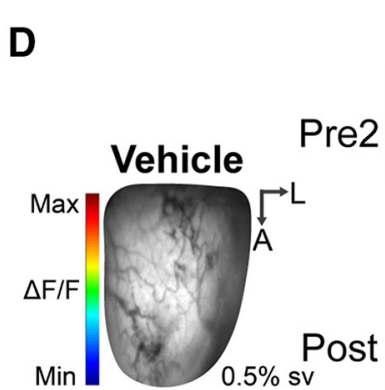

E

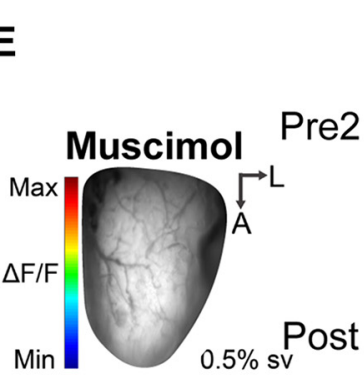

E5

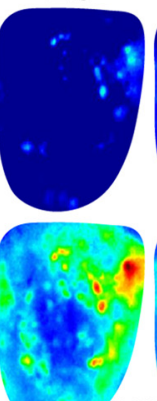

E4
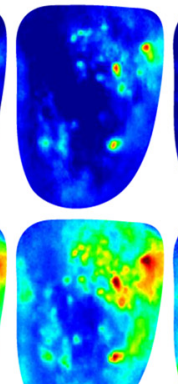

$10 \%$<smiles>[BH3-]</smiles>

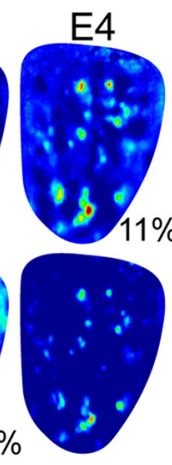

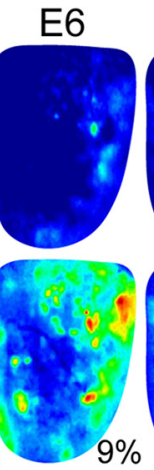

BZ
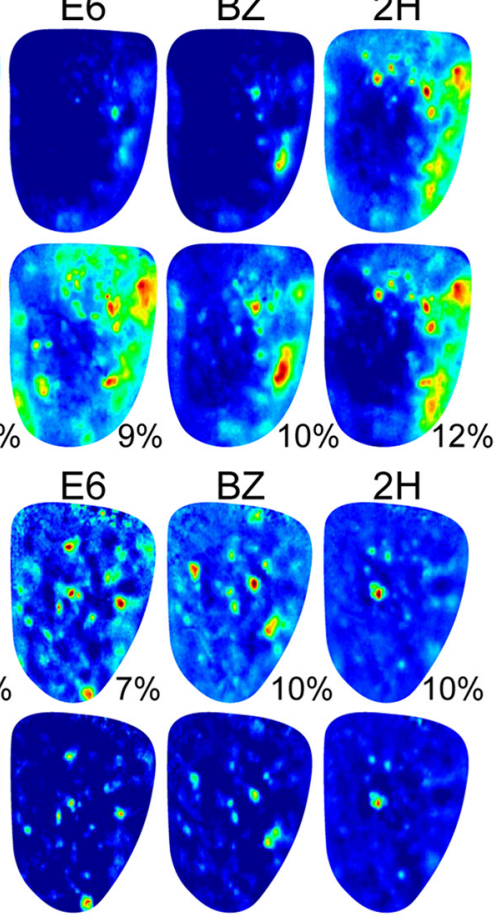

F

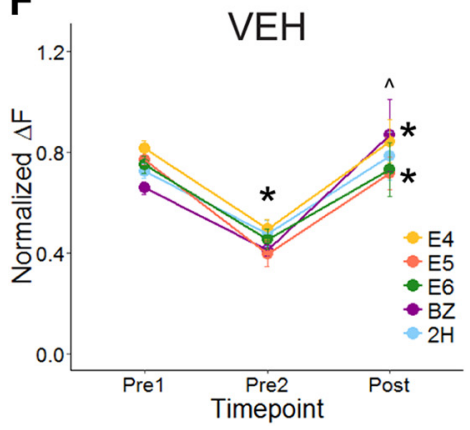

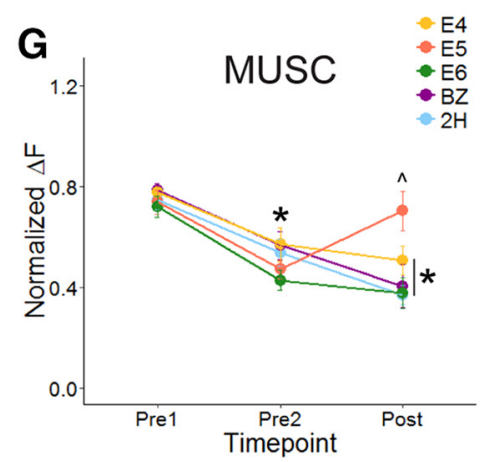
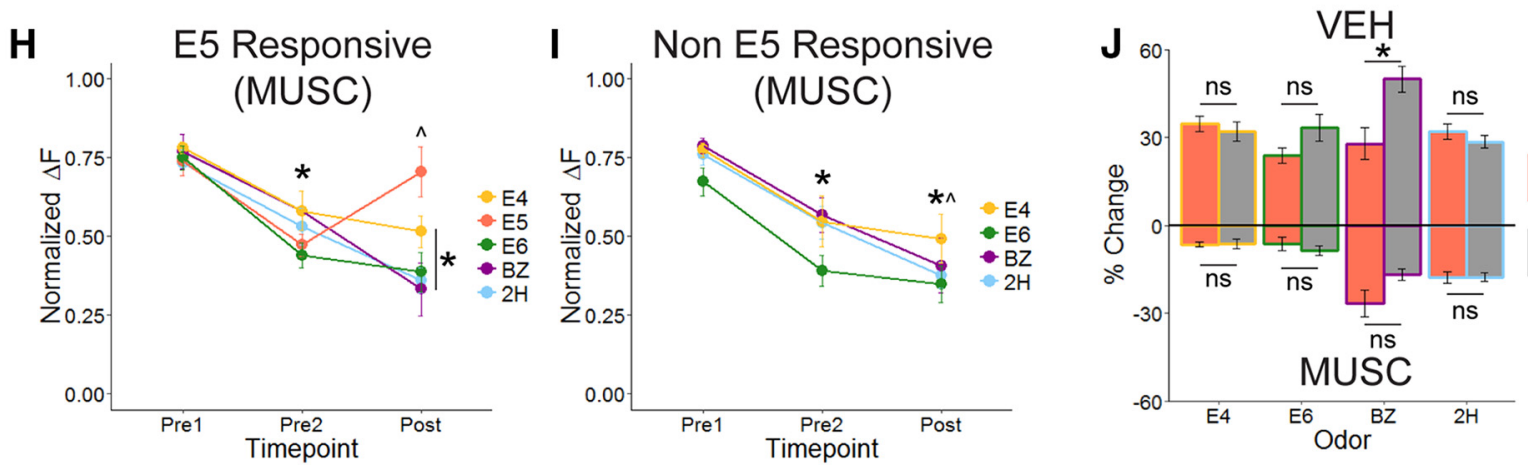

E5 Responsive

Non E5

Responsive

Figure 9. Generalized, but not (S-specific, glomerular enhancements are associative learning-dependent. $\boldsymbol{A}$, Schematic detailing time course of experiments, the odors used (top), and paradigms for both imaging (above dotted line) and behavioral (below dotted line) experiments, including drug administration. $B, C$, Mice were exposed to all five odors $24 \mathrm{~h}$ after training and freezing was measured. In mice receiving VEH infusions before training, presentations of E5 elicited significantly more freezing than baseline, indicating they learned to fear the CS. Additionally, VEH mice generalized fear to all odors, except BZ. In contrast, mice receiving MUSC infusions before training did not freeze significantly more to presentations of E5 than baseline, indicating that they did not learn. ${ }^{*} p<0.001 . \boldsymbol{D}, \boldsymbol{E}$, Resting light-intensity frames and pseudocolored averaged Pre2 and Post maps from representative VEH (D) and MUSC $(\boldsymbol{E})$ mice, where the pseudocolor scale is based on the day with the maximum observed responses (Post for Vehicle, Pre2 for Muscimol for all odors except E5) to avoid oversaturation of pseudocolored maps. Although scaling color in this manner makes Pre2 responses appear significantly weaker in the VEH group, amplitude of Pre2 responses are similar across mice for each odor. The approximate value of the maximum observed responses ( $\Delta F / F$ ) used for pseudocolor scale is listed to the right of each odor. $\boldsymbol{F}, \boldsymbol{G}$, Normalized glomerular responses over time for each imaged odor for all VEH $(\boldsymbol{F})$ and MUSC $(\boldsymbol{E})$ mice. Responses for all odors in both groups significantly decrease from Pre1 to Pre2. Responses to all odors are significantly increased after training in VEH mice. In contrast, only responses to presentations of E5 are enhanced in MUSC mice; all other odor responses are continually suppressed. In MUSC mice, the same post-training suppression of nonconditioned odors occurs regardless of whether glomeruli are $\mathrm{E} 5 \mathrm{Responsive} \mathrm{(H)}$ or Non-E5 Responsive $(I) .{ }^{*} p<0.001$ from Pre1, $\wedge p<0.001$ from Pre2. J, Glomerular overlap does not affect the percentage change of glomerular responses (Pre2 to Post) in VEH (top; with the exception of BZ) or MUSC (bottom) mice, indicating glomerular changes are odor- rather than glomerulus-specific (J). Data presented mean \pm SEM. ${ }^{*} p<0.05$. 
A

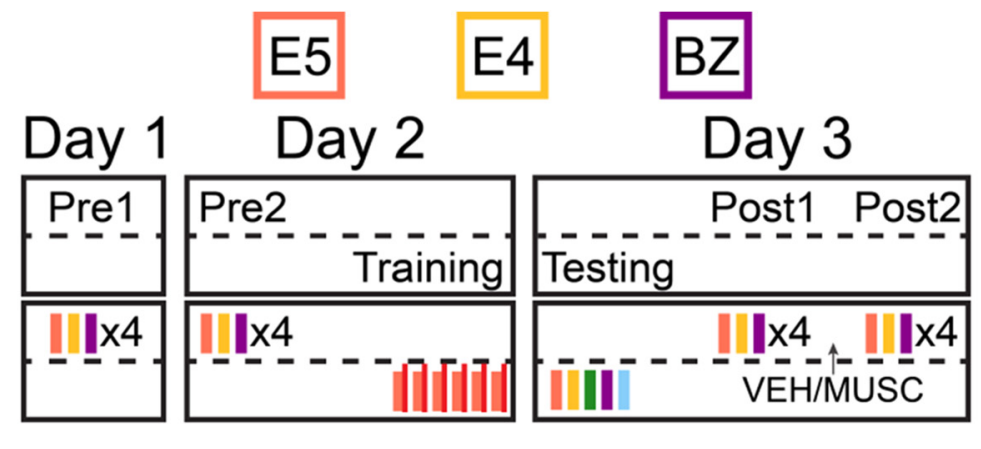

C

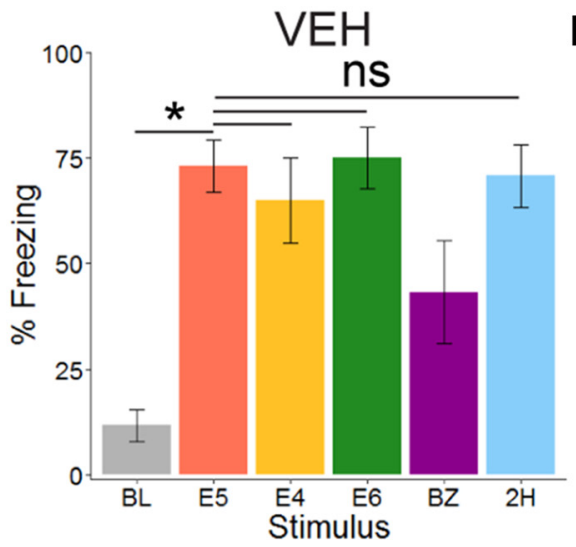

E

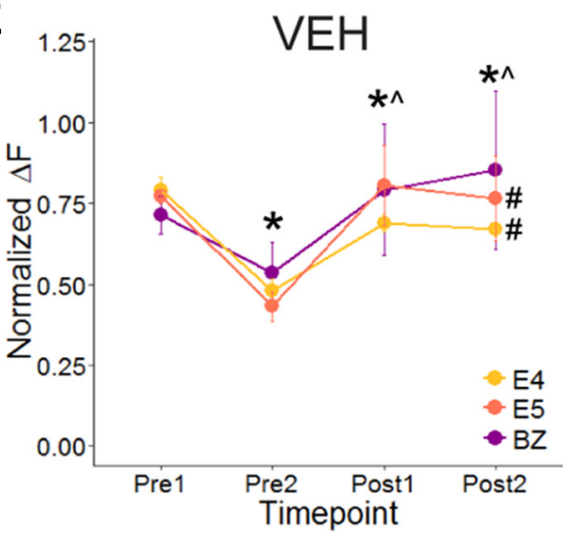

D

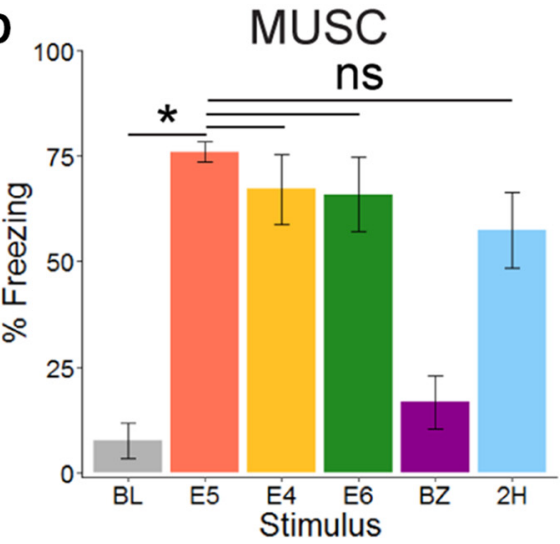

F

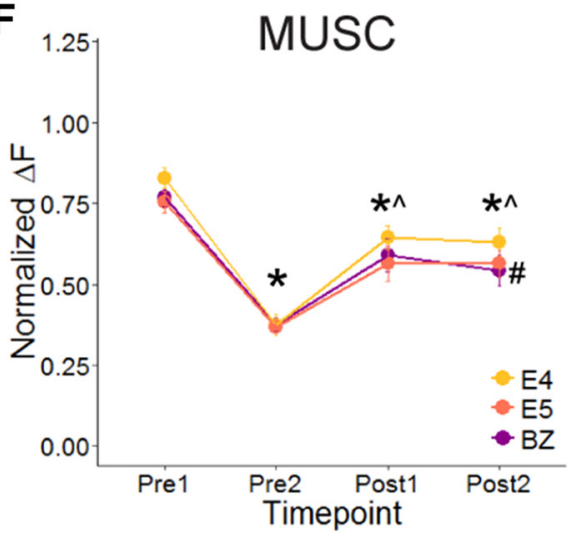

B

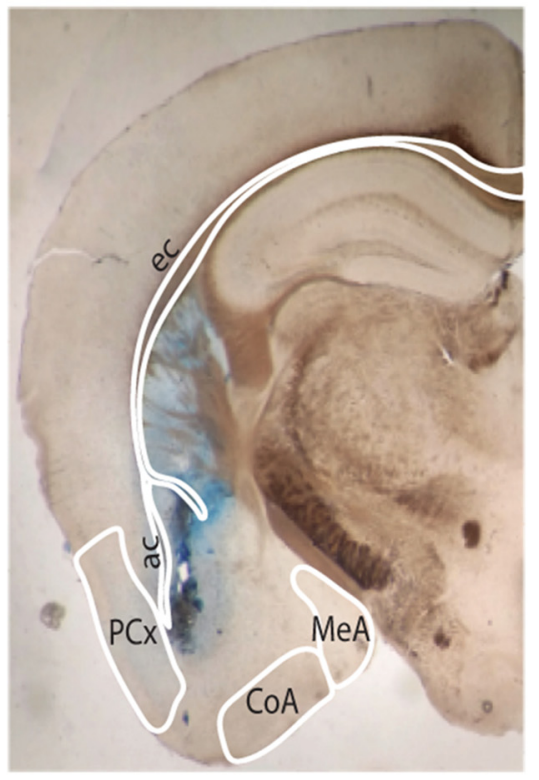

Figure 10. Amygdala inactivation during expression of learning does not impact glomerular responses. $\boldsymbol{A}$, Schematic detailing time course of experiments, the odors used (top), and paradigms for both imaging (above dotted line) and behavioral (below dotted line) experiments, including drug administration. $\boldsymbol{B}$, Confirmation of BLA cannula placement and evaluation of possible MUSC spread. PCx, Piriform cortex; $C 0 A$, cortical amygdala; MeA, medial amygdala; ac, amygdalar capsule; ec, external capsule. $C$, $\boldsymbol{D}$, Freezing to all five odors was measured $24 \mathrm{~h}$ after training and confirms that both groups of mice froze significantly more to the $\mathrm{CS}$ than baseline and generalized that fear to all odors except BZ. ${ }^{*} p<0.001$. E, F, Averaged glomerular responses for both groups decreased significantly from Pre1 and Pre2, but were reinstated after learning (Post1). Infusions of either VEH or MUSC occurred between Post1 and Post2. Following infusions, both groups exhibited mixed-profile responses, with some odor responses increasing, others decreasing, and some not changing significantly. Additional analysis quantifying the average percentage change from Post1 to Post2 (G) indicates no significant difference between groups, indicating BLA inactivation does not alter glomerular responses in a meaningful way. ${ }^{*} p<0.001$ from Pre1, $\wedge p<0.001$ from Pre2, $\# p<0.001$ from Post1.

groups $\left(t_{(744)}=0.679, p=0.497\right.$, Mean \pm SEM: VEH $=$ $-1.202 \pm 0.634 \%$, MUSC $=-1.739 \pm 0.480 \%)$, indicating inactivation of the BLA after learning did not reduce glomerular responses relative to VEH control responses (Fig. 10G). Given MUSC infusion during the Post imaging session did not affect glomerular responses relative to controls, we surmise amygdalar activity during expression does not modulate OB glomerular responses, indicating that $\mathrm{OB}$ enhancements are not a result of BLA activation following learning. Although amygdalar activity does not appear to modulate $\mathrm{OB}$ responses in this case, it may still impact other brain regions to contribute to behavioral fear generalization.

\section{Discussion}

Pairing awake in vivo calcium imaging with behavior, we investigated the effect of classical olfactory aversive learning on glomerular odor responses. The results demonstrate that odor familiarity leads to reduced glomerular responses that are evident as early as the second day of odor exposure. These responses decrease over days, with learning producing significant and long-lasting enhancement of glomerular odor responses for the CS as well as neutral, nonconditioned odors. Enhancements are not specific to CSresponsive glomeruli, indicating global potentiation. Moreover, the spatial representations of nonconditioned odors become more correlated to the CS representation, possibly contributing 
to broad behavioral fear generalization by increasing perceptual similarity. Increased glomerular responses following fear conditioning are not caused by altered respiration or global fear states as a result of shock learning, nor can it be suppressed by inactivating the BLA after learning occurs. Chiefly, this study demonstrates two distinct mechanisms responsible for glomerular enhancements: an associative learning-independent mechanism, which supports CS-specific enhancements, and an associative learning-dependent mechanism, which promotes nonspecific potentiation associated with generalization. To our knowledge, this is the first report of distinct mechanisms that mediate specific versus generalized response potentiation following classical fear learning.

These findings expand upon previous reports of learninginduced changes in olfactory regions in insects (Faber et al., 1999; Blum et al., 2009; Chen et al., 2015), rodents (Jones et al., 2008; Sevelinges et al., 2008; Barnes et al., 2011), and humans (Li et al., 2008). Recent imaging studies in anesthetized rodents demonstrate increased responses to the CS in OSNs, M/T cells, and inhibitory periglomerular cells (Fletcher, 2012; Kass et al., 2013; Kass and McGann, 2017). Our anesthetized experiment confirms these findings. In addition, we observed both increased and decreased post-training glomerular responses to the CS in our anesthetized experiment, as previously reported (Fletcher, 2012), whereas almost all glomeruli were significantly enhanced after training in awake mice. This likely reflects differences between anesthetized and awake conditions such as activity of intrabulbar inhibitory circuits or state-dependent centrifugal modulation (Tsuno et al., 2008; Blauvelt et al., 2013; Wachowiak et al., 2013; Rothermel and Wachowiak, 2014; Boyd et al., 2015), though it is also possible that robust expression of learning-induced glomerular plasticity requires wakefulness (Kato et al., 2012).

Importantly, most previous studies did not explore generalization, instead either restricting analysis to the CS or using a discriminative conditioning paradigm that results in CS-specific fear. Mice that learn to fear only the trained odorant display CSspecific enhancements (Kass et al., 2013). In contrast, classical training paradigms produce broad behavioral generalization (Pavesi et al., 2012; Kass and McGann, 2017), even to dissimilar odorants and completely novel odorants (Fig. 10A,C,D). Our report is the first to examine the relationship between behavioral generalization and altered sensory representations in awake mice. Odor coding in the awake condition is characterized by narrowly tuned $\mathrm{M} / \mathrm{T}$ cell responses and enhanced inhibitory interneuron activity and centrifugal input (Kato et al., 2012; Wachowiak et al., 2013; Boyd et al., 2015). The combination of these factors likely plays an important role in olfactory processing, especially in the context of learning. Our awake training and imaging paradigms revealed broad behavioral generalization and global glomerular potentiation in the same mice, implying that $\mathrm{OB}$ plasticity reflects the associative learning event. In addition, we report increased representational similarity following olfactory conditioning. Given that spatiotemporal patterns of glomerular activity form the initial basis of odor identity, it is possible that such changes might increase perceptual similarity and bias downstream systems toward generalization. Together, these lines of evidence suggest that different training paradigms may generate global or specific sensory plasticity, which in turn could serve as an initial neural basis for generalized or specific behavioral responses.

\section{Potential distinct mechanisms of experience-induced glomerular plasticity}

We demonstrate, in the absence of reinforcement, glomerular responses decrease across days. These findings support previous studies establishing that stimulus familiarity leads to reduced responses (Buonviso et al., 1998; Buonviso and Chaput, 2000; McNamara et al., 2008; Gdalyahu et al., 2012; Kato et al., 2012). While we did not explore the cause of the nonassociative learning suppression, this likely arises from plasticity within OB inhibitory interneurons that are reduced under anesthesia, as this effect is not seen when imaging OSN glomerular responses (Kato et al., 2012). Interestingly, we detect less suppression in anesthetized than awake mice, which is consistent with this idea.

In terms of associative learning, we used MUSC to transiently inactivate the BLA during acquisition (Wilensky et al., 1999; Ribeiro et al., 2011) to prevent fear learning. It is possible that MUSC infusions also impact areas outside of the BLA, such as other portions of the amygdala or piriform cortex. Although we assessed likely drug spread and believe the external and amygdalar capsules prevent lateral spread (Fig. 10B), we cannot completely rule out the possibility that MUSC may also affect piriform cortex. However, the goal of MUSC injections into BLA was not to specifically assess the contribution of BLA to post-training glomerular enhancements but a method to block learning and evaluate whether enhancements were associative learning dependent, which was accomplished.

Even though MUSC mice did not acquire learned fear of E5, they exhibited augmented glomerular responses to E5. The fact that the CS-specific enhancements remain even when associative learning is blocked suggests that the first mechanism, which produces CS-specific enhancements, does not require associative fear learning. One possible explanation for this is experience-dependent structural changes within the glomerular layer itself. Fear conditioning can increase glomerular size (Jones et al., 2008); however, such structural changes are caused by increased number of OSN axons innervating glomeruli. We do not believe this drives our effect as the previous study trained mice over several days and weeks, allowing time for anatomical reorganization that our training paradigm likely does not allow. Alternatively, CS-specific plasticity could occur in the glomerular layer downstream of OSNs. Studies in pups reported odor-specific synaptic tagging in the OB glomerular and external plexiform layers as well as synaptic AMPA receptor insertion following odor experience (Modarresi et al., 2016), which could amplify glomerular responses. However, the enhancement we observed in the absence of learning was specific to E5, with no enhanced responses to other odors that activate those glomeruli. This suggests that the mechanisms responsible are not structural changes within OB neurons, as this should lead to glomerulus-specific enhancements. Instead, the mechanism underlying the odor-specific enhancements likely involves changes within OB circuitry encoding E5. Odor exposure and learning can decrease broad activation of granule cells (Woo et al., 1996), which should result in disinhibition of M/T cells and could be reflected in glomerular activity (Johnson et al., 1995; Huang et al., 2016). Further studies aimed at changes in specific cell types within the $\mathrm{OB}$ are needed to confirm this hypothesis.

The second mechanism is a global, nonspecific enhancement of all glomeruli that is associative learning-dependent. Using an auditory fear paradigm in conjunction with OB imaging, we demonstrated that learning-induced enhancements are not a result of global fear states indiscriminately enhancing all incoming sensory information. However, it is possible that fear states modulate sensory processing in a modality-specific manner. Therefore, we 
additionally inactivated BLA by infusing MUSC to test whether suppressing fear centers during expression affects learning-induced glomerular enhancements. Although we detected small differences in glomerular responsivity to some of the odors after MUSC infusion, those differences were no different from those exhibited by mice following VEH infusion (Fig. 10F), suggesting BLA activity during expression does not modulate glomerular responses and is not the direct cause of learning-induced glomerular enhancements. Again, it is possible MUSC infusions affected more than just BLA and future studies should employ more spatially precise methods if they intend to parse out contributions of exact regions. Together, this evidence points to learning-induced changes in centrifugal modulation of $\mathrm{OB}$ responsivity from higher brain regions as a likely candidate. There is considerable feedback from cortical and neuromodulatory regions that can enhance $\mathrm{OB}$ responses to olfactory stimuli (Price and Powell, 1970; Haberly and Price, 1978; Mouret et al., 2009; Fletcher and Chen, 2010; Otazu et al., 2015; Linster and Cleland, 2016). Neuromodulatory systems can enhance representations of olfactory stimuli by acting on either local inhibitory interneurons or $\mathrm{M} / \mathrm{T}$ cells. For example, both acetylcholine and serotonin release in the $\mathrm{OB}$ and enhance $\mathrm{M} / \mathrm{T}$ cells odor responses (Rothermel et al., 2014; Bendahmane et al., 2016; Brunert et al., 2016; Kapoor et al., 2016). Both of these systems are involved in fear learning (Pavesi et al., 2012; Bauer, 2015; Wilson and Fadel, 2017) and could serve as the mechanism behind global enhancements following fear conditioning.

\section{Potential impact}

Importantly, OB glomerular responses constitute initial olfactory processing. $\mathrm{M} / \mathrm{T}$ cells project odor information to cortical centers where it is integrated with other relevant information before ultimately driving behavioral responses. Generalized learning-induced enhancement of glomerular responses could serve to increase perceptual similarity of experienced odors, as evidenced by increased representational correlations, and thereby contribute to fear generalization. Previous reports in the olfactory system demonstrate olfactory discrimination learning decorrelates odor responses in areas of olfactory cortex (Kadohisa and Wilson, 2006), possibly decreasing perceptual similarity and making fine discrimination between odorants easier. In fact, decorrelated cortical representations of odor mixtures predict behavioral discrimination of those mixtures (Barnes et al., 2011), reinforcing the idea that olfactory representational similarity confers perceptual similarity in a way that influences behavior. Similar learning-induced effects are reported in other sensory and model systems, confirming that sensory learning alters sensory processing and correlates with behavior (Edeline et al., 1993; Mukai et al., 2007; Mundy et al., 2014; Smith et al., 2015). Together, any learning-induced transformation, even at the earliest stages of processing, that increases or decreases the representational similarity of sensory stimuli may prime generalized or specific behavioral responses, respectively. Importantly, the amount of behavioral generalization does not perfectly match the magnitude of learning-induced glomerular potentiation. For example when E5 is the CS, mice occasionally freeze significantly less while demonstrating the largest glomerular potentiation to BZ (Fig. $7 B, F$ ). There are two possibilities to explain such a phenomenon. Although there is large enhancement to BZ responsive glomeruli, those that are BZ Responsive but Non-E5 Responsive are most enhanced (Fig. 7J, top), possibly decreasing perceptual similarity and contributing to less behavioral generalization. It is also possible that the global potentiation serves on a more basic level to increase olfactory information being sent to cortical processing areas, which contribute to behavioral responses.
The present results emphasize that fear learning increases representational similarity of sensory stimuli at the earliest stages of processing, which may bias downstream fear regions toward generalization. As disrupted fear generalization is a hallmark of anxiety and trauma and stressor-related disorders (Cahill and Foa, 2007; Lissek et al., 2010, 2014), understanding the mechanisms and brain regions underlying fear generalization may inform future treatments of this pathological behavior as well as our basic understanding of the mechanisms underlying long-term memory.

\section{References}

Bakin JS, Weinberger NM (1990) Classical conditioning induces CSspecific receptive field plasticity in the auditory cortex of the guinea pig. Brain Res 536:271-286. CrossRef Medline

Barnes DC, Chapuis J, Chaudhury D, Wilson DA (2011) Odor fear conditioning modifies piriform cortex local field potentials both during conditioning and during post-conditioning sleep. PLoS One 6:e18130. CrossRef Medline

Bauer EP (2015) Serotonin in fear conditioning processes. Behav Brain Res 277:68-77. CrossRef Medline

Bendahmane M, Ogg MC, Ennis M, Fletcher ML (2016) Increased olfactory bulb acetylcholine bi-directionally modulates glomerular odor sensitivity. Sci Rep 6:25808. CrossRef Medline

Blauvelt DG, Sato TF, Wienisch M, Knöpfel T, Murthy VN (2013) Distinct spatiotemporal activity in principal neurons of the mouse olfactory bulb in anesthetized and awake states. Front Neural Circuits 7:46. CrossRef Medline

Blum AL, Li W, Cressy M, Dubnau J (2009) Short- and long-term memory in Drosophila require cAMP signaling in distinct neuron types. Curr Biol 19:1341-1350. CrossRef Medline

Boyd AM, Kato HK, Komiyama T, Isaacson JS (2015) Broadcasting of cortical activity to the olfactory bulb. Cell Rep 10:1032-1039. CrossRef Medline

Bozza T, McGann JP, Mombaerts P, Wachowiak M (2004) In vivo imaging of neuronal activity by targeted expression of a genetically encoded probe in the mouse. Neuron 42:9-21. CrossRef Medline

Brunert D, Tsuno Y, Rothermel M, Shipley MT, Wachowiak M (2016) Celltype-specific modulation of sensory responses in olfactory bulb circuits by serotonergic projections from the raphe nuclei. J Neurosci 36:6820 6835. CrossRef Medline

Buck L, Axel R (1991) A novel multigene family may encode odorant receptors: a molecular basis for odor recognition. Cell 65:175-187. CrossRef Medline

Buonviso N, Chaput M (2000) Olfactory experience decreases responsiveness of the olfactory bulb in the adult rat. Neuroscience 95:325-332. CrossRef Medline

Buonviso N, Gervais R, Chalansonnet M, Chaput M (1998) Short-lasting exposure to one odour decreases general reactivity in the olfactory bulb of adult rats. Eur J Neurosci 10:2472-2475. CrossRef Medline

Cahill SP, Foa EB (2007) In: handbook of PTSD: science and practice (Friedman MJ, Keane TM, Resick PA, eds), pp 55-77. New York, NY: Guilford.

Chen JY, Marachlian E, Assisi C, Huerta R, Smith BH, Locatelli F, Bazhenov M (2015) Learning modifies odor mixture processing to improve detection of relevant components. J Neurosci 35:179-197. CrossRef Medline

Chen Q, Cichon J, Wang W, Qiu L, Lee SJ, Campbell NR, Destefino N, Goard MJ, Fu Z, Yasuda R, Looger LL, Arenkiel BR, Gan WB, Feng G (2012) Imaging neural activity using Thyl-GCaMP transgenic mice. Neuron 76: 297-308. CrossRef Medline

Chettih SN, McDougle SD, Ruffolo LI, Medina JF (2011) Adaptive timing of motor output in the mouse: the role of movement oscillations in eyelid conditioning. Front Integr Neurosci 5:72. CrossRef Medline

Edeline JM, Pham P, Weinberger NM (1993) Rapid development of learninginduced receptive field plasticity in the auditory cortex. Behav Neurosci 107: 539-551. CrossRef Medline

Faber T, Joerges J, Menzel R (1999) Associative learning modifies neural representations of odors in the insect brain. Nat Neurosci 2:74-78. CrossRef Medline

Fletcher ML (2011) Analytical processing of binary mixture information by olfactory bulb glomeruli. PLoS One 6:e29360. CrossRef Medline

Fletcher ML (2012) Olfactory aversive conditioning alters olfactory bulb 
mitral/tufted cell glomerular odor responses. Front Syst Neurosci 6:16. CrossRef Medline

Fletcher ML, Chen WR (2010) Neural correlates of olfactory learning: critical role of centrifugal neuromodulation. Learn Mem 17:561-570. CrossRef Medline

Fletcher ML, Masurkar AV, Xing J, Imamura F, Xiong W, Nagayama S, Mutoh H, Greer CA, Knöpfel T, Chen WR (2009) Optical imaging of postsynaptic odor representation in the glomerular layer of the mouse olfactory bulb. J Neurophysiol 102:817-830. CrossRef Medline

Gdalyahu A, Tring E, Polack PO, Gruver R, Golshani P, Fanselow MS, Silva AJ, Trachtenberg JT (2012) Associative fear learning enhances sparse network coding in primary sensory cortex. Neuron 75:121-132. CrossRef Medline

Haberly LB, Price JL (1978) Association and commissural fiber systems of the olfactory cortex of the rat: II. Systems originating in the olfactory peduncle. J Comp Neurol 181:781-807. CrossRef Medline

Heiney SA, Wohl MP, Chettih SN, Ruffolo LI, Medina JF (2014) Cerebellardependent expression of motor learning during eyeblink conditioning in head-fixed mice. J Neurosci 34:14845-14853. CrossRef Medline

Herry C, Ciocchi S, Senn V, Demmou L, Müller C, Lüthi A (2008) Switching on and off fear by distinct neuronal circuits. Nature 454:600-606. CrossRef Medline

Huang L, Ung K, Garcia I, Quast KB, Cordiner K, Saggau P, Arenkiel BR (2016) Task learning promotes plasticity of interneuron connectivity maps in the olfactory bulb. J Neurosci 36:8856-8871. CrossRef Medline

Johansen JP, Cain CK, Ostroff LE, LeDoux JE (2011) Molecular mechanisms of fear learning and memory. Cell 147:509-524. CrossRef Medline

Johnson BA, Woo CC, Duong H, Nguyen V, Leon M (1995) A learned odor evokes an enhanced fos-like glomerular response in the olfactory bulb of young rats. Brain Res 699:192-200. CrossRef Medline

Jones SV, Choi DC, Davis M, Ressler KJ (2008) Learning-dependent structural plasticity in the adult olfactory pathway. J Neurosci 28:13106-13111. CrossRef Medline

Kadohisa M, Wilson DA (2006) Separate encoding of identity and similarity of complex familiar odors in piriform cortex. Proc Natl Acad Sci U S A 103:15206-15211. CrossRef Medline

Kapoor V, Provost AC, Agarwal P, Murthy VN (2016) Activation of raphe nuclei triggers rapid and distinct effects on parallel olfactory bulb output channels. Nat Neurosci 19:271-282. CrossRef Medline

Kass MD, McGann JP (2017) Persistent, generalized hypersensitivity of olfactory bulb interneurons after olfactory fear generalization. Neurobiol Learn Mem 146:47-57. CrossRef Medline

Kass MD, Rosenthal MC, Pottackal J, McGann JP (2013) Fear learning enhances neural responses to threat-predictive sensory stimuli. Science 342: 1389-1392. CrossRef Medline

Kato HK, Chu MW, Isaacson JS, Komiyama T (2012) Dynamic sensory representations in the olfactory bulb: modulation by wakefulness and experience. Neuron 76:962-975. CrossRef Medline

Letzkus JJ, Wolff SB, Meyer EM, Tovote P, Courtin J, Herry C, Lüthi A (2011) A disinhibitory microcircuit for associative fear learning in the auditory cortex. Nature 480:331-335. CrossRef Medline

Li W, Howard JD, Parrish TB, Gottfried JA (2008) Aversive learning enhances perceptual and cortical discrimination of indiscriminable odor cues. Science 319:1842-1845. CrossRef Medline

Linster C, Cleland TA (2016) Neuromodulation of olfactory transformations. Curr Opin Neurobiol 40:170-177. CrossRef Medline

Lissek S, Rabin S, Heller RE, Lukenbaugh D, Geraci M, Pine DS, Grillon C (2010) Overgeneralization of conditioned fear as a pathogenic marker of panic disorder. Am J Psychiatry 167:47-55. CrossRef Medline

Lissek S, Kaczkurkin AN, Rabin S, Geraci M, Pine DS, Grillon C (2014) Generalized anxiety disorder is associated with overgeneralization of classically conditioned fear. Biol Psychiatry 75:909-915. CrossRef Medline

Maren S (2003a) What the amygdala does and doesn't do in aversive learning. Learn Mem 10:306-308. CrossRef Medline

Maren S (2003b) The amygdala, synaptic plasticity, and fear memory. Ann N Y Acad Sci 985:106-113. CrossRef Medline

Maren S (2005) Synaptic mechanisms of associative memory in the amygdala. Neuron 47:783-786. CrossRef Medline

McAfee SS, Ogg MC, Ross JM, Liu Y, Fletcher ML, Heck DH (2016) Minimally invasive highly precise monitoring of respiratory rhythm in the mouse using an epithelial temperature probe. J Neurosci Methods 263: 89-94. CrossRef Medline
McNamara AM, Magidson PD, Linster C, Wilson DA, Cleland TA (2008) Distinct neural mechanisms mediate olfactory memory formation at different timescales. Learn Mem 15:117-125. CrossRef Medline

Modarresi S, Mukherjee B, McLean JH, Harley CW, Yuan Q (2016) CaMKII mediates stimulus specificity in early odor preference learning in rats. J Neurophysiol 116:404-410. CrossRef Medline

Mori K, Takahashi YK, Igarashi KM, Yamaguchi M (2006) Maps of odorant molecular features in the mammalian olfactory bulb. Physiol Rev 86:409433. CrossRef Medline

Mouret A, Murray K, Lledo PM (2009) Centrifugal drive onto local inhibitory interneurons of the olfactory bulb. Ann N Y Acad Sci 1170:239-254. CrossRef Medline

Mukai I, Kim D, Fukunaga M, Japee S, Marrett S, Ungerleider LG (2007) Activations in visual and attention-related areas predict and correlate with the degree of perceptual learning. J Neurosci 27:11401-11411. CrossRef Medline

Mundy ME, Downing PE, Honey RC, Singh KD, Graham KS, Dwyer DM (2014) Brain correlates of experience-dependent changes in stimulus discrimination based on the amount and schedule of exposure. PLoS One 9:e101011. CrossRef Medline

Ogg MC, Bendahamane M, Fletcher ML (2015) Habituation of glomerular responses in the olfactory bulb following prolonged odor stimulation reflects reduced peripheral input. Front Mol Neurosci 8:53. CrossRef Medline

Otazu GH, Chae H, Davis MB, Albeanu DF (2015) Cortical feedback decorrelates olfactory bulb output in awake mice. Neuron 86:1461-1477. CrossRef Medline

Pavesi E, Gooch A, Lee E, Fletcher ML (2012) Cholinergic modulation during acquisition of olfactory fear conditioning alters learning and stimulus generalization in mice. Learn Mem 20:6-10. CrossRef Medline

Pavlov IP (1927) Conditioned reflexes. New York, NY: Oxford UP.

Price JL, Powell TP (1970) An experimental study of the origin and course of the centrifugal fibres to the olfactory bulb in the rat. J Anat 107:215-237. Medline

Resnik J, Paz R (2015) Fear generalization in the primate amygdala. Nat Neurosci 18:188-190. CrossRef Medline

Ribeiro AM, Barbosa FF, Munguba H, Costa MS, Cavalcante JS, Silva RH (2011) Basolateral amygdala inactivation impairs learned (but not innate) fear response in rats. Neurobiol Learn Mem 95:433-440. CrossRef Medline

Rogan MT, Stäubli UV, LeDoux JE (1997) Fear conditioning induces associative long-term potentiation in the amygdala. Nature 390:604-607. CrossRef Medline

Rothermel M, Wachowiak M (2014) Functional imaging of cortical feedback projections to the olfactory bulb. Front Neural Circuits 8:73. CrossRef Medline

Rothermel M, Carey RM, Puche A, Shipley MT, Wachowiak M (2014) Cholinergic inputs from basal forebrain add an excitatory bias to odor coding in the olfactory bulb. J Neurosci 34:4654-4664. CrossRef Medline

Sadrian B, Wilson DA (2015) Optogenetic stimulation of lateral amygdala input to posterior piriform cortex modulates single-unit and ensemble odor processing. Front Neural Circuits 9:81. CrossRef Medline

Sevelinges Y, Sullivan RM, Messaoudi B, Mouly AM (2008) Neonatal odorshock conditioning alters the neural network involved in odor fear learning at adulthood. Learn Mem 15:649-656. CrossRef Medline

Shusterman R, Smear MC, Koulakov AA, Rinberg D (2011) Precise olfactory responses tile the sniff cycle. Nat Neurosci 14:1039-1044. CrossRef Medline

Smith GB, Sederberg A, Elyada YM, Van Hooser SD, Kaschube M, Fitzpatrick D (2015) The development of cortical circuits for motion discrimination. Nat Neurosci 18:252-261. CrossRef Medline

Spors H, Grinvald A (2002) Spatio-temporal dynamics of odor representations in the mammalian olfactory bulb. Neuron 34:301-315. CrossRef Medline

Spors H, Wachowiak M, Cohen LB, Friedrich RW (2006) Temporal dynamics and latency patterns of receptor neuron input to the olfactory bulb. J Neurosci 26:1247-1259. CrossRef Medline

Storace DA, Cohen LB (2017) Measuring the olfactory bulb input-output transformation reveals a contribution to the perception of odorant concentration invariance. Nat Commun 8:81. CrossRef Medline 
Tsuno Y, Kashiwadani H, Mori K (2008) Behavioral state regulation of dendrodendritic synaptic inhibition in the olfactory bulb. J Neurosci 28: 9227-9238. CrossRef Medline

Verhagen JV, Wesson DW, Netoff TI, White JA, Wachowiak M (2007) Sniffing controls an adaptive filter of sensory input to the olfactory bulb. Nat Neurosci 10:631-639. CrossRef Medline

Wachowiak M, Cohen LB (2001) Representation of odorants by receptor neuron input to the mouse olfactory bulb. Neuron 32:723-735. CrossRef Medline

Wachowiak M, Economo MN, Díaz-Quesada M, Brunert D, Wesson DW, White JA, Rothermel M (2013) Optical dissection of odor information processing in vivo using GCaMPs expressed in specified cell types of the olfactory bulb. J Neurosci 33:5285-5300. CrossRef Medline

Walker DL, Paschall GY, Davis M (2005) Glutamate receptor antagonist infusions into the basolateral and medial amygdala reveal differential contributions to olfactory vs context fear conditioning and expression. Learn Mem 12:120-129. CrossRef Medline

Weinberger NM (2007) Auditory associative memory and representational plasticity in the primary auditory cortex. Hear Res 229:54-68. CrossRef Medline

Wesson DW, Carey RM, Verhagen JV, Wachowiak M (2008) Rapid encoding and perception of novel odors in the rat. PLoS Biol 6:e82. CrossRef Medline

Wilensky AE, Schafe GE, LeDoux JE (1999) Functional inactivation of the amygdala before but not after auditory fear conditioning prevents memory formation. J Neurosci 19:RC48. CrossRef Medline

Wilson MA, Fadel JR (2017) Cholinergic regulation of fear learning and extinction. J Neurosci Res 95:836-852. CrossRef Medline

Woo CC, Oshita MH, Leon M (1996) A learned odor decreases the number of fos-immunopositive granule cells in the olfactory bulb of young rats. Brain Res 716:149-156. CrossRef Medline 